\title{
Placental glycogen stores and fetal growth: insights from genetic mouse models
}

\author{
Simon J Tunster, Erica D Watson, Abigail L Fowden and Graham J Burton \\ Centre for Trophoblast Research, Department of Physiology, Development and Neuroscience, Physiology Building, \\ Downing Site, Cambridge, UK \\ Correspondence should be addressed to S J Tunster; Email: sjt95@cam.ac.uk
}

\begin{abstract}
The placenta performs a range of crucial functions that support fetal growth during pregnancy, including facilitating the supply of oxygen and nutrients to the fetus, removal of waste products from the fetus and the endocrine modulation of maternal physiology. The placenta also stores glucose in the form of glycogen, the function of which remains unknown. Aberrant placental glycogen storage in humans is associated with maternal diabetes during pregnancy and pre-eclampsia, thus linking placental glycogen storage and metabolism to pathological pregnancies. To understand the role of placental glycogen in normal and complicated pregnancies, we must turn to animal models. Over 40 targeted mutations in mice demonstrate the defects in placental cells that store glycogen and suggest that placental glycogen represents a source of readily mobilized glucose required during periods of high fetal demand. However, direct functional evidence is currently lacking. Here, we evaluate these genetic mouse models with placental phenotypes that implicate glycogen trophoblast cell differentiation and function to illuminate the common molecular pathways that emerge and to better understand the relationship between placental glycogen and fetal growth. We highlight the current limitations in exploring the key questions regarding placental glycogen storage and metabolism and define how to experimentally overcome these constraints. Reproduction (2020) 159 R213-R235
\end{abstract}

\section{Introduction}

The placenta is a unique organ that exists only during pregnancy to perform a diverse range of functions that collectively support optimal fetal growth while maintaining maternal well-being. Arguably, the principal role of the placenta is to mediate the supply of oxygen and nutrients from the mother to fetus (Burton \& Fowden 2015). The placenta also removes waste products from the fetal circulation and forms a physical barrier that affords some protection against certain pathogens and toxins (Gude et al. 2004). Furthermore, the placenta also synthesizes and secretes hormones into the mother's blood to adapt maternal physiology and behavior, ultimately to ensure that the pregnancy is sustained and fetal growth is supported (Napso et al. 2018). In addition to facilitating glucose transport, the placenta metabolizes glucose for its own use and stores it in the form of the multi-branched polysaccharide glycogen. The purpose of placental glycogen stores in normal pregnancy remains unclear. The most widely accepted theory is that placental glycogen stores ensure that fetal glucose supply is maintained at times of maximal demand, such as during late gestation (Barash \& Shafrir 1990, Coan et al. 2006). However, direct experimental evidence to support such a function is currently lacking.

\section{Placental glycogen in humans}

Despite the earliest reference to glycogen storage in the human placenta dating to the early twentieth century (Driessen 1907), understanding its role during normal or complicated pregnancies has remained an elusive goal. In the human placenta, glycogen is predominantly found in the cytotrophoblast cells (Wislocki \& Bennett 1943), with the highest levels in the distal cytotrophoblast closest to the decidua (Georgiades et al. 2002). In uncomplicated pregnancies, placental glycogen content peaks toward the end of the first trimester before declining towards term (Villee 1953, Boyd 1959, Robb \& Hytten 1976). Aberrant glycogen storage was reported in gestational diabetes (Heijkenskjold \& Gemzell 1957, Gabbe et al. 1972, Diamant et al. 1982, Desoye et al. 1992, Gheorman et al. 2013) and preeclampsia (PE) (Arkwright et al. 1993, Tsoi et al. 2003), suggesting a possible role in the pathogenesis of these two common pregnancy complications. The relevance of aberrant glycogen storage in the context of human pregnancy complications has been reviewed elsewhere (Akison et al. 2017). However, one hypothesis suggests that, in diabetic pregnancies, the placenta stores excess glucose as glycogen to protect the fetus from hyperglycaemia, thus limiting fetal overgrowth (Desoye et al. 2002). 
Considerable constraints limit our ability to explore placental glycogen function in humans, such as the lack of available tissue at the appropriate developmental stage. Accordingly, it is necessary to turn to the mouse model, which benefits from large litter sizes, a short gestation period that allows for the investigation of early pregnancy and a similar genome to humans that is easily manipulated. There are 47 known mouse models with targeted mutations that display phenotypes associated with the trophoblast cell subtype that stores glycogen. A common feature among these placental mutants is that fetal growth is co-ordinately affected. Therefore, the use of these mutant mouse lines will help to elucidate the normal physiological role of placental glycogen and may provide further insight to the relevance of placental glycogen in the human placenta during normal and complicated pregnancies.

\section{Placental development in the mouse}

The mouse is a particularly useful model for the human placenta, since they are both hemochorial, architecturally similar and express many of the same genes that regulate placental development and function (Rossant \& Cross 2001). In particular, imprinted genes, which are characterized by expression derived wholly, or predominantly, from one or other parental allele, exert significant influence on placental development in both humans (Frost \& Moore 2010) and mice (Tunster et al. 2013). Furthermore, the mouse placenta also accumulates glycogen stores in a specialized trophoblast cell subtype called the glycogen trophoblast (GlyT), some of which interact intimately with the maternal decidua (Rampon et al. 2005, Coan et al. 2006, Bouillot et al. 2006). For this reason, GlyT cells share similarities with human cytotrophoblast cells and establish the mouse as an ideal model in which to elucidate the function(s) of placental glycogen stores.

In the mouse, GlyT cells appear as clusters in the junctional zone $(\mathrm{Jz})$ of the mature placenta, before a proportion of these cells invade the maternal decidua to congregate around maternal spiral arteries (Adamson et al. 2002). When considering how defects in placental glycogen storage and metabolism emerge, it is important to consider when GlyT first arise during placental development and whether defective GlyT differentiation is the primary cause of altered placental glycogen content. Development of the mouse placenta under normal circumstances has been extensively reviewed elsewhere (Rossant \& Cross 2001, Watson \& Cross 2005). Briefly, by implantation at embryonic day (E) 4.5 , the mouse blastocyst comprises a layer of trophectoderm that surrounds the inner cell mass (ICM). The trophectoderm cells immediately adjacent to the ICM proliferate to give rise to two main trophoblast progenitor populations: the ectoplacental cone (EPC), which will differentiate to yield cells of the centrally located Jz that is predominantly endocrine in function and the extraembryonic ectoderm (ExE), which will eventually give rise to the labyrinth zone (Lz) where, when vascularized by fetal capillaries, nutrient, gas and waste exchange between maternal and fetal blood circulations occurs (Fig. 1).

To date, nine trophoblast cell sub-types are known to differentiate from these progenitor populations. These include the spongiotrophoblast (SpT) and GlyT cells, which share a common EPC progenitor and together with parietal trophoblast giant cells (P-TGCs) comprise the mature Jz. SpT cells function predominantly in the production of hormones, including members of the $\mathrm{Prl}$ (prolactin/placental lactogen-related) and Psg (pregnancy specific glycoprotein) gene families. The GlyT lineage is named for the abundant stores of glycogen that they accumulate and metabolize during gestation. In total, five TGC sub-types have been identified. Based upon lineage tracing, gene-expression profiles and spatial localization within the placenta (Fig. 1), it is hypothesized that most of the TGCs also derive from the EPC (Simmons et al. 2007, Gasperowicz et al. 2013). TGCs associate with the maternal blood sinuses throughout the placenta and secrete hormones into the maternal circulation to modulate maternal physiology and placenta function. Sinusoidal-TGCs (S-TGCs) are located within the Lz, and together with a bilayer of syncytiotrophoblast (SynT-I and SynT-II) cells derived from the ExE, they create a trilaminar cellular arrangement that separates the maternal circulation from the extensively branched fetal vasculature (Adamson et al. 2002, Watson \& Cross 2005, Simmons et al. 2008a).

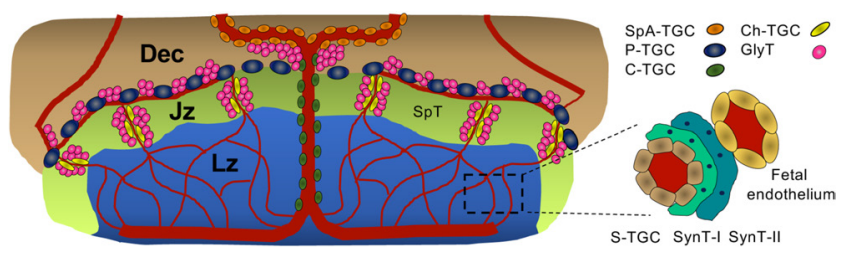

Figure 1 Structure and trophoblast lineages of the mature mouse placenta: The mature mouse placenta comprises three structurally and functionally distinct layers: the maternal decidua (Dec), junctional zone $(\mathrm{Jz})$ and labyrinth zone $(\mathrm{Lz})$. The junctional zone predominantly comprises the spongiotrophoblast (SpT) and nonmigratory glycogen trophoblast (GlyT) cells. A proportion of GlyT migrate to the maternal decidua where they associate with maternal spiral arteries bringing maternal blood to the placenta. Five trophoblast giant cell sub-types have been described based on the localization on gene expression patterns: the parietal TGCs (P-TGCs) form a discontinuous cell layer at the boundary between the Jz and maternal decidua; spiral artery-associated TGCs (SpA-TGCs) line maternal spiral arteries through the decidua; canal-TGCs (C-TGCs) line maternal blood canals through the Jz and Lz; sinusoidal-TGCs (S-TGCs) replace the endothelial layer of maternal blood sinuses within the Lz and channel-TGCs (Ch-TGCs) surround the channels that traverse the Jz draining maternal blood from the placenta. Together with the S-TGCs, two layers of syncytiotrophoblast form the trilaminar structure of the murine labyrinth. 
Based on lineage tracing experiments (Simmons \& Cross 2005), GlyT cells share a common Tpbpa ${ }^{+}$EPC progenitor with SpT cells and arise early in development. Periodic acid-Schiff (PAS) staining, which is a general staining method used to detect polysaccharides (e.g. glycogen) in addition to mucosubstances (e.g. glycoproteins and glycolipids), demonstrates that small quantities of glycogen are stored by GlyT from E5.5 (Tesser et al. 2010), suggesting that GlyT are specified soon after implantation. An early lineage split of the GlyT and SpT populations is further suggested by expression of the GlyT-specific marker genes Pcdh 12 and Aldh1a3 in a subset of EPC cells from E7.5 and $\sim$ E8.5, respectively (Rampon et al. 2005, Bouillot et al. 2006, Outhwaite et al. 2015). GlyT number expands nearly 300-fold between E12.5 and E16.5 before declining $\sim 60 \%$ by E18.5 (Coan et al. 2006). This expansion coincides with a marked increase in PAS staining from E12.5 (Adamson et al. 2002), which distinguishes GlyT from the adjacent SpT cells (Fig. 2A, B and C). By comparison, the SpT population increases less than four-fold during the same period, with a modest $\sim 20 \%$ reduction by E18.5 (Coan et al. 2006). During this developmental time frame, placental
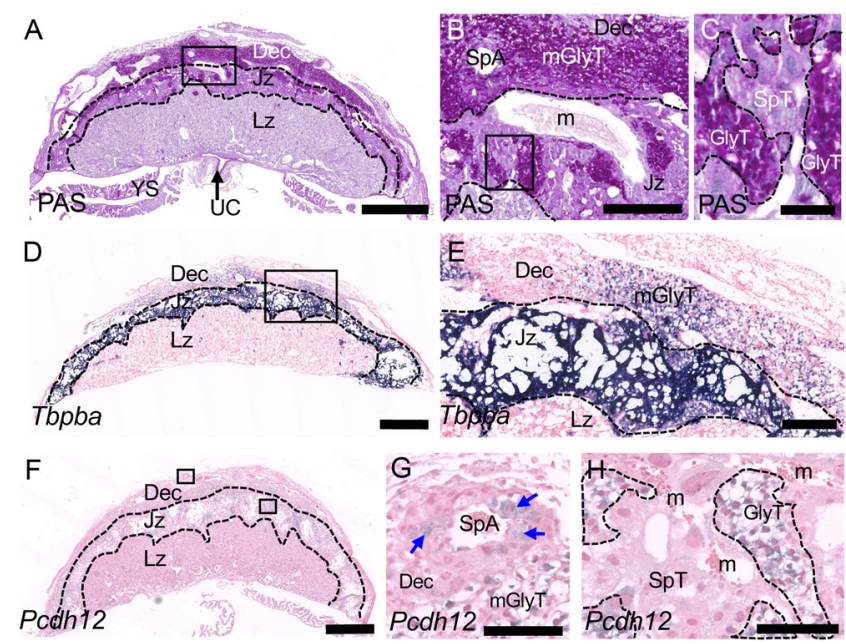

Figure 2 Histological methods for assessing glycogen trophoblast cells in the mouse placenta at E14.5. Histological sections of WT (C57BL/6J) mouse placentas at E14.5 stained using (A, B and C) Periodic acid-Schiff (PAS) stain (dark pink) that labels glycogen, glycoproteins and glycolipids, (D and E) Tpbpa RNA via an in situ hybridization probe (dark purple) that stains cells derived from the ectoplacental cone (e.g. spongiotrophoblast (SpT) and glycogen trophoblast (GlyT)) and (F, G and H) Pcdh12 RNA via an in situ hybridization probe (dark purple) that stains GlyT. Nuclei are stained using (A, B and $C$ ) haematoxylin (blue) or (D, E, F, G, H) nuclear fast red (pink). Dec, maternal decidua; Jz, junctional zone; Lz, labyrinth zone; YS, yolk sac; UC, umbilicus (black arrow); SpA, spiral artery; m, maternal blood sinusoid; mGlyT, migratory GlyT (blue arrows). Dotted lines separate major placenta layers or trophoblast cell populations. Boxes represent regions shown in higher magnification to the right. Scale bars: $A, D, F=1 \mathrm{~mm} ; \mathrm{B}, \mathrm{E}=250 \mu \mathrm{m} ; \mathrm{C}=50 \mu \mathrm{m} ; \mathrm{G}$, $\mathrm{H}=100 \mu \mathrm{m}$. glycogen stores peak at $\sim$ E15.5 before declining by $\sim 50 \%$ at E18.5 (Lopez et al. 1996) as the GlyT cell population diminishes. Even though both GlyT and SpT cells continue to express the Jz-marker gene Tpbpa in the mature placenta (Lescisin et al. 1988) (Fig. 2D and E), other GlyT-specific markers have been described, including the gap-junction genes Gjb3 (Cx31) and Gjb5 (Cx31.1), which are localised to GlyT cells from $\sim$ E12.5 (Coan et al. 2006) and E13.5 (Zheng-Fischhofer et al. 2007), respectively, alongside persistent expression of Pcdh12 (Fig. 2F, G and H).

\section{The putative role of placental glycogen}

Studies in animal models have led to the hypothesis that placental glycogen stores provide a source of glucose to support fetal growth during late gestation (Coan et al. 2006). This hypothesis is supported by two observations: glycogen acts as the primary energy store in animals and placental glycogen diminishes toward the end of pregnancy coincident with a period of rapid fetal growth. However, little experimental evidence currently exists to directly support such a function. The location of GlyT cells next to maternal blood sinuses may provide some indication as to the ultimate destination of the glucose released from placental glycogen stores. For instance, from E12.5, some GlyT invade the decidua where they localize in close proximity to maternal spiral arteries and by E16.5 account for $\sim 30 \%$ of the total GlyT population (Redline et al. 1993, Coan et al. 2006, Gasperowicz et al. 2013) (Fig. 1). Based on this association, it is possible that migratory GlyT cells metabolize glycogen into glucose for transport into the maternal blood entering the placenta for eventual fetal uptake. Indeed, large lacunae form in the decidua by E17.5 that are presumed to result from the lysis of multiple GlyT in the vicinity (Bouillot et al. 2006). In contrast, populations of non-migratory GlyT cells cluster in close proximity to channels in the $\mathrm{Jz}$ that drain maternal blood from the placenta (Gasperowicz et al. 2013) (Fig. 1). Whether these GlyT cells release glucose or other factors, such as hormones, into maternal blood to influence maternal physiology in preparation for parturition and lactation (Napso et al. 2018) to indirectly support fetal growth and well-being is yet to be determined. Beyond location, the migratory and non-migratory GlyT populations are distinguishable by expression of distinct $\mathrm{Prl}$ genes: migratory GlyT express Prl7b1, while non-migratory GlyT express Prl6a1 (Simmons et al. 2008b). Further experiments are necessary to explore the functional differences between these GlyT sub-types. Simultaneously, it is also possible that placental glycogen stores might provide energy directly to the placenta, since it is a highly metabolic organ that consumes a considerable proportion of the glucose delivered to it (Hay 1995). Indeed, placental glycogen stores might fuel hormone production by the placenta (e.g. Prl and Psg gene family members), which 
increases dramatically toward the term (McLellan et al. 2005, Simmons et al. 2008b).

How placental glycogen is metabolized is not well understood. Glucagon might play a role in stimulating the release of glycogen stores from GlyT (Coan et al. 2006). Yet, placental glycogen content is unaltered in mice deficient for the glucagon receptor (Ouhilal et al. 2012), indicating that an alternative pathway might be involved. However, only a small number of glucagon-receptor mutants were examined at a single developmental time-point with no consideration of fetal sex. Fetal sex was shown to influence the placental glycogen content, at least in the spiny mouse $\left(\mathrm{O}^{\prime}\right.$ Connell et al. 2013). Therefore, a role for glucagon in regulating glycogen metabolism cannot currently be excluded. Additional models are required to more fully understand the enzymes that are important for glycogen metabolism in the mouse placenta.

\section{Common functionality of genes involved in GlyT development and function}

Of the 47 mutant mouse lines that are known to exhibit GlyT phenotypes (with or without aberrant glycogen storage), 38 different genes are represented. As the list lengthens, common genetic pathways and gene classifications have emerged as important players in GlyT formation and function. The majority of these genes can be assigned to at least one of three functional groups (Table 1): imprinted and X-linked genes, cell signalling genes and genes involved in transcriptional regulation.

\section{Imprinted and X-linked genes}

Imprinted genes represent an unusual class of autosomal gene that are characterized by complete or partial parental-allele-biased expression. This means that gene expression is derived wholly, or predominantly, from either the maternally inherited allele (i.e. maternally expressed) or paternally inherited allele (i.e. paternally expressed) in one or more tissues. In excess of 100 imprinted genes have been reported in the mouse, many of which are known to regulate placental development and function (Tunster et al. 2013). A broad role for imprinted genes in regulating the GlyT lineage has been reviewed previously (Lefebvre 2012), whereby four genes (Ascl2, Cdkn1c, lgf2 and Phlda2) that reside within $\mathrm{a} \sim 1 \mathrm{Mb}$ imprinted region on mouse distal chromosome 7 were discussed in detail. In addition to these genes, the paternally expressed DIk1, Peg3 and Peg10 genes are also implicated in regulating the GlyT lineage and/or placental glycogen stores (Table 1), further emphasizing the importance of imprinted genes in regulating placental glycogen stores.

A special class of imprinted genes is theX-chromosomelinked genes. To ensure similar gene dosage between males and females, one $X$ chromosome in female cells is silenced. In extraembryonic lineages of female mouse conceptuses, the paternally inherited X-chromosome is preferentially silenced (Takagi \& Sasaki 1975). A role for X-linked genes in regulating placental glycogen storage is demonstrated by mice that inherited only a single paternally inherited $\mathrm{X}$ chromosome $(\mathrm{XpO})$ and display an expansion of the GlyT population (He et al. 2017). In support of this hypothesis, GlyT phenotypes were reported to varying degrees in loss-of-function models of four X-linked genes (i.e. Plac1, Ldoc1, Wdr 1 and Esx1) (Table 1). The functional convergence of imprinted and X-linked genes in regulating placental glycogen storage is consistent with the established role of imprinted genes in modulating fetal nutrient supply across the placenta (Angiolini et al. 2006, Tunster et al. 2013) and with the purported function of placental glycogen stores in providing an energy source to support fetal growth during late gestation. With the majority of imprinted genes exhibiting placental expression in the mouse, it will be of interest to explore whether other imprinted genes are involved in regulating placental glycogen storage.

\section{Cell-cell signalling}

Studies of mutant mouse lines that report glycogen storage defects that arise secondary to SpT phenotypes implicate a role for SpT-derived signals in the regulation of placental glycogen metabolism. For instance, genetic knockout or overexpression of the maternally expressed imprinted gene Phlda2 causes an expansion or reduction of the SpT population, respectively (Tunster et al. 2010, 2014, 2015). Unaltered expression of the GlyT marker genes Pcdh12 and Gjb3 suggested that there was no overt effect on GlyT population size in either model. However, placental glycogen content closely paralleled the SpT phenotype, with a reduced SpT population leading to diminished glycogen content and an expanded SpT population associated with increased glycogen storage (Tunster et al. 2010, 2014, 2015). These studies implicate cell-to-cell signalling between SpT and GlyT, though the specific pathways that mediate this effect are unclear. A clue might lie within the Crim 1 knockout model. Crim 1 encodes for a transmembrane protein that mediates signal transduction by binding growth factors (e.g. vascular endothelial growth factor A; VEGF-A) to the cell surface. While Crim 1 mRNA expression is limited to SpT cells, the GlyT population expands in the absence of CRIM1 function (Pennisi et al. 2012). Therefore, CRIM1 might regulate a SpT-derived factor that signals to GlyT to regulate their proliferation (Pennisi et al. 2012).

Further evidence for a role of SpT-derived signals in modulating placental glycogen stores is provided by a comparison of Phlda2 null conceptuses and their WT littermates with strain-matched control litters. Loss of 


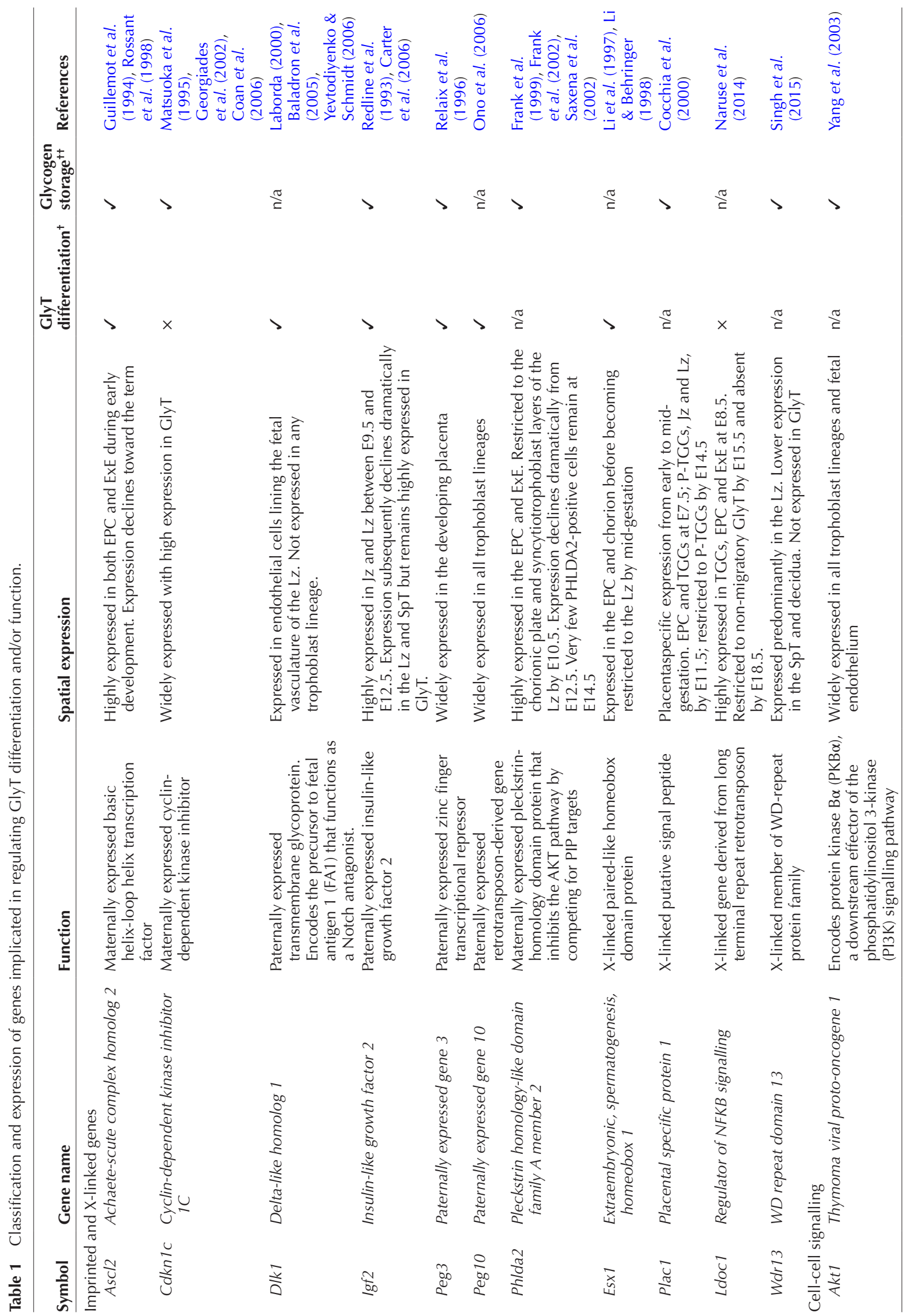




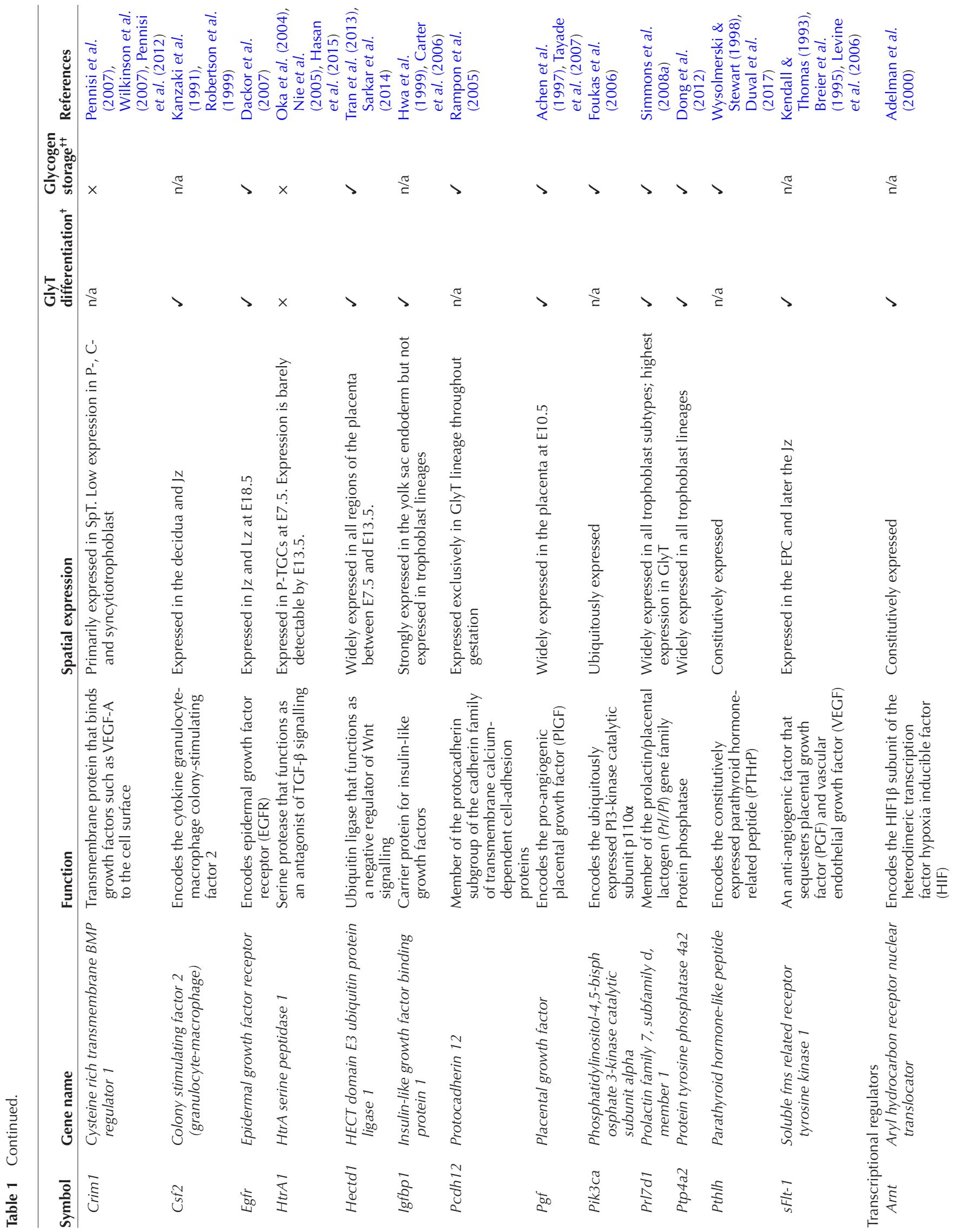



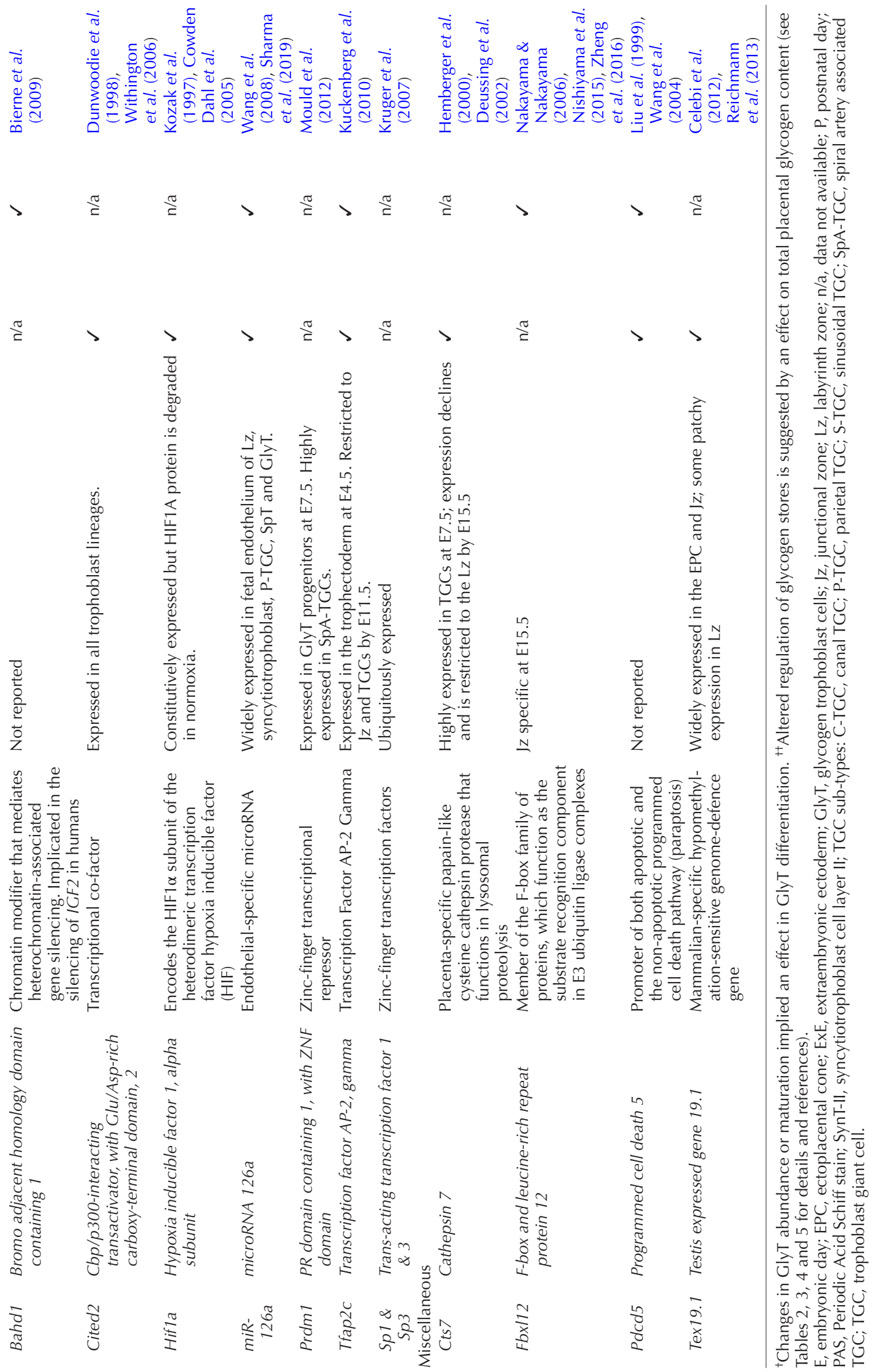
function of Phlda2 results in expansion of the Jz (Frank et al. 2002), which is attributable to a disproportionate increase in the SpT population (Tunster et al. 2015). While there was no overt effect on GlyT cell number, an accumulation of glycogen in placentas from Phlda2 null their WT littermates was apparent at E18.5. One explanation might be that the entire litter was exposed to an enhanced endocrine-signalling environment caused by SpT expansion in Phlda2 null placentas resulting in excessive placental glycogen storage that potentially deprives the fetuses of nutrients (Tunster et al. 2015). However, it is not possible to exclude a role for broader effects on maternal physiology in impairing fetal growth in this model.

We have further identified fourteen genes that encode for specific components of cell-signalling pathways that might help to establish the importance of cellcell signalling in the regulation of placental glycogen content (Table 1). These genes include signalling molecules such as cytokines (Csf2), hormones (Pthlh, Prl7d1) and growth factors (Pgf), receptors (Egfr) and downstream effectors, such as kinases (Akt1, Pik3ca) and phosphatases (Ptp4a2). Some of these genes encode for key intermediates in a diverse range of signalling pathways, namely VEGF (e.g. Crim1), epidermal growth factor (EGF) (e.g. Egfr) and transforming growth factor (TGF) (e.g. HtrA1) pathways.

In particular, aberrant AKT signalling is implicated in GlyT phenotypes associated with genetic knockouts of Ptp4a2, Tfap2c, Igf2 or Phlda2 (Frank et al. 1999, Saxena et al. 2002, Dong et al. 2012, Takao et al. 2012, Sharma et al. 2016, Sferruzzi-Perri et al. 2017). This, combined with the fact that loss of function of Akt1 itself impairs placental glycogen storage (Yang et al. 2003), indicates that the AKT pathway is key to this process. AKT signalling is known to regulate specific cellular processes including growth, proliferation, metabolism and survival (Yu \& Cui 2016, Hermida et al. 2017, Manning \& Toker 2017). Specific to its role in glycogen storage, AKT also regulates glycogenesis through the inhibition of glycogen synthase kinase 3 (GSK3), a negative regulator of glycogen synthase (Cross et al. 1995, Diehl et al. 1998). Other models that show changes in the expression of Igf2 or Phlda2 (e.g. Pcdh 12 knockout (Rampon et al. 2008)) might also implicate AKT-signalling defects in their GlyT phenotypes. While aberrant AKT signalling was reported in the placentas of human FGR infants (Yung et al. 2008), placental glycogen storage has not yet been investigated in the context of human FGR to date.

Ablation of $A k t 1$, which encodes for protein kinase $\mathrm{B} \alpha$ (PKB $\alpha$ ), causes fetal and placental growth restriction (Yang et al. 2003). A near complete loss of glycogen-containing trophoblast cells was reported (Yang et al. 2003), though this result was based solely on examination of PASstained placenta sections. The absence of PAS staining is more likely to indicate a failure to accumulate glycogen, rather than ablation of the GlyT lineage. Therefore, this model should be revisited for a more detailed analysis of the GlyT phenotype, including determination of spatiotemporal expression of markers such as Pcdh 12 (Bouillot et al. 2006), Gjb3 (Coan et al. 2006), Aldh1a3 (Outhwaite et al. 2015) and biochemical analysis of glycogen content (Lo et al. 1970). Regardless, the result is consistent with the role of AKT in regulating GSK3 and, indirectly, glycogen synthase (Yang et al. 2003).

Upstream regulators of AKT signalling include PRL2 and IGF2, both of which have been implicated in placental development. The Ptp4a2 gene encodes for the protein phosphatase PRL2 and, when knocked out, the placentas were small in size due to a substantially reduced Jz defined by a near complete loss of SpT with only a few non-migratory GlyT remaining (Dong et al. 2012). While PAS staining was reduced, placental glycogen content was not directly quantified (Dong et al. 2012). Ptp4a2 $2^{-/}$placentas also exhibited reduced AKT phosphorylation (Dong et al. 2012), indicating that PRL2 is important for this process. The associated Ptp4a2 $\%$ fetuses were growth restricted at E16.5. In fetal tissues, AKT and MAPK (mitogen activated protein kinase) pathways are activated via IGF2 signalling mediated primarily through binding IGF1R (insulin-like growth factor 1 receptor) (Forbes \& Westwood 2008, Sferruzzi-Perri et al. 2017). However, the absence of a placental phenotype in Igf1r null mice suggests that IGF2 acts through an alternative, unknown receptor in the placenta (Baker et al. 1993, Efstratiadis 1998). Whether IGF2 activates AKT signalling in the placenta is unclear, and a detailed assessment of AKT signalling in the placenta of Igf2 mutants is required. Additionally, further work is warranted to explore the broad role of AKT signalling in regulating the placental glycogen stores by utilizing mouse models with known GlyT phenotypes.

\section{Transcriptional regulators}

The GlyT population is highly dynamic, with the number of GlyT cells increasing by nearly 300-fold between E12.5 and E16.5, and switching from an apparently glycogenic state to a glycogenolytic state (Lopez et al. 1996). These changes implicate major shifts in transcriptional regulation to modulate placental glycogen metabolism. A broad role for transcriptional regulators in modulating placental glycogen storage and/or the GlyT lineage has not been previously recognized. We identified eight genes encoding specific transcriptional regulators that are implicated in the development and/or function of the GlyT lineage (Table 1). One example is the endothelial-specific microRNA miR-126a (miR-126), which when ablated leads to global hypermethylation associated with dysregulated expression of placenta- 
specific genes (e.g. Prl6a1, Pcdh12 and Tpbpa) and imprinted genes (e.g. Igf2, Phlda2 and Cdkn1C) (Sharma et al. 2019). Genetic ablation of miR-126a results in Jz hyperplasia, attributable to a specific expansion of the GlyT population, without a change in SpT abundance. Consequently miR-126a ${ }^{-/}$placentas accumulated $\sim 50 \%$ more glycogen than controls and were associated with fetal growth restriction at E15.5 (Sharma et al. 2019). The specific targets of miR-126a are yet to be determined. Further work is required to fully elucidate the transcriptional networks involved in regulating the GlyT lineage and glycogen storage.

\section{Using genetic mouse models to understand the function of placental glycogen}

The association of altered placental glycogen storage with human pregnancy complications supports an important role for glycogen in achieving a successful pregnancy outcome (reviewed in Akison et al. 2017). The majority of mouse models with GlyT phenotypes show evidence of fetal growth restriction (FGR), which is consistent with the putative role of placental glycogen in supporting fetal growth (Tables 2 and 3). In contrast, the remaining models showed GlyT phenotypes that were either associated with normal, enhanced or undetermined effects on fetal growth (Table 4) or embryonic lethality around mid-gestation (Table 5) that precluded a meaningful assessment of fetal growth.

In our evaluation of the literature, we observed that the extent to which GlyT phenotypes are characterized varies considerably between studies. Indeed, only a minority of these models were assessed using a direct biochemical determination of placental glycogen content. Instead, reduced glycogen storage or mobilization was inferred from one or more of the following methods: reduced (or absent) PAS staining; reduced GlyT abundance as determined by histology and/or reduced genetic marker expression for GlyT cells and mislocalization of GlyT within the Lz or a failure of GlyT cells to migrate to the decidua. As a result, there is a need for established criteria in describing GlyT phenotypes and glycogen storage and metabolic defects. We identified four key parameters for characterizing GlyT phenotypes: (1.) GlyT lineage specification and differentiation by assessing lineage marker expression, (2.) GlyT cell number, (3.) GlyT localization and degree of migration into the decidua and (4.) quantification of total placental glycogen content using a biochemical assay (Lo et al. 1970). A collective evaluation of these genetic mutants using these criteria will help to separate GlyT developmental defects from metabolic/storage defects and improve our understanding of how placental glycogen stores support growth.

\section{Reduced placental glycogen content is frequently associated with fetal growth restriction}

Several mouse models that demonstrate a glycogen storage deficit are also associated with FGR (Table 2). It is well known that IGF2 is an important regulator of fetal and placental growth (DeChiara et al. 1990, Constância et al. 2005). Igf2 mRNA is highly expressed in the GlyT lineage (Redline et al. 1993, Georgiades et al. 2002, Coan et al. 2006), and constitutive deletion of Igf2 results in reduced GlyT abundance and placental glycogen content (Lopez et al. 1996). Deletion of the placenta-specific lgf2 transcript (Igf2PO) results in a similar reduction of GlyT cell number (Sferruzzi-Perri et al. 2011), even though the Igf2P0 transcript accounts for only $10 \%$ of total placental lgf2 (Moore et al. 1997). While constitutive deletion of lgf2 results in a $50 \%$ reduction in fetal weight (DeChiara et al. 1990), Igf2PO mutants are $25 \%$ lighter than controls (Constância et al. 2005), at least partially attributing FGR to a placental defect. However, the contribution of placental glycogen is unclear, as glycogen content was not directly assessed in the $\lg 2 \mathrm{PO}$ mutants.

Human placentas exhibiting elevated expression of PHLDA2 are frequently linked with FGR (reviewed in Jensen et al. 2014), although placental glycogen stores have not been investigated in these placentas. Analysis of a mouse model with overexpression of Phlda2 demonstrates that placental glycogen content is reduced by $50 \%$ of controls. However, the effect on glycogen storage is likely secondary to a reduction in the Prl8a8 ${ }^{+}$SpT population, since there was no overt effect on expression of the GlyT markers Pcdh12 or Gjb3 (Tunster et al. 2010, 2014, 2015). The effect on fetal growth in the Ph/da2 overexpression model is complex and dependent upon the genetic background of the mouse, even though similar placental defects are apparent between strains. For instance, fetal growth was asymmetrically restricted when on the 129S2/SvHsd background (Salas et al. 2004, Tunster et al. 2010), but was unaffected on the C57BL/ 6 background (Tunster et al. 2014). Since genetically WT placentas on the C57BL/6 background naturally accumulate more than twice the glycogen content of 129S2/SvHsd placentas (Tunster et al. 2012), fetal growth might be protected on the $\mathrm{C} 57 \mathrm{BL} / 6$ background.

Even though GlyT are important for fetal growth, these cells are not essential to fetal survival. GlyT cells were absent in mutant mouse lines, whereby the expression of Ascl 2 was at $~ 50 \%$ of endogenous levels (Ascl $2^{\text {LacZ/Del } 7 A l}$ or $D e l^{7 A l} /+$ mutants). Placentas either demonstrated a lack of PAS stain and/or Pcdh12 expression at E15.5. The associated fetuses survived to term, albeit exhibiting growth restriction of 15-20\% (Lefebvre et al. 2009, Oh-McGinnis et al. 2011, Bogutz et al. 2018). In contrast, Ascl2 null placentas lack the EPC progenitor cells that give rise to the SpT and GlyT resulting in embryonic 


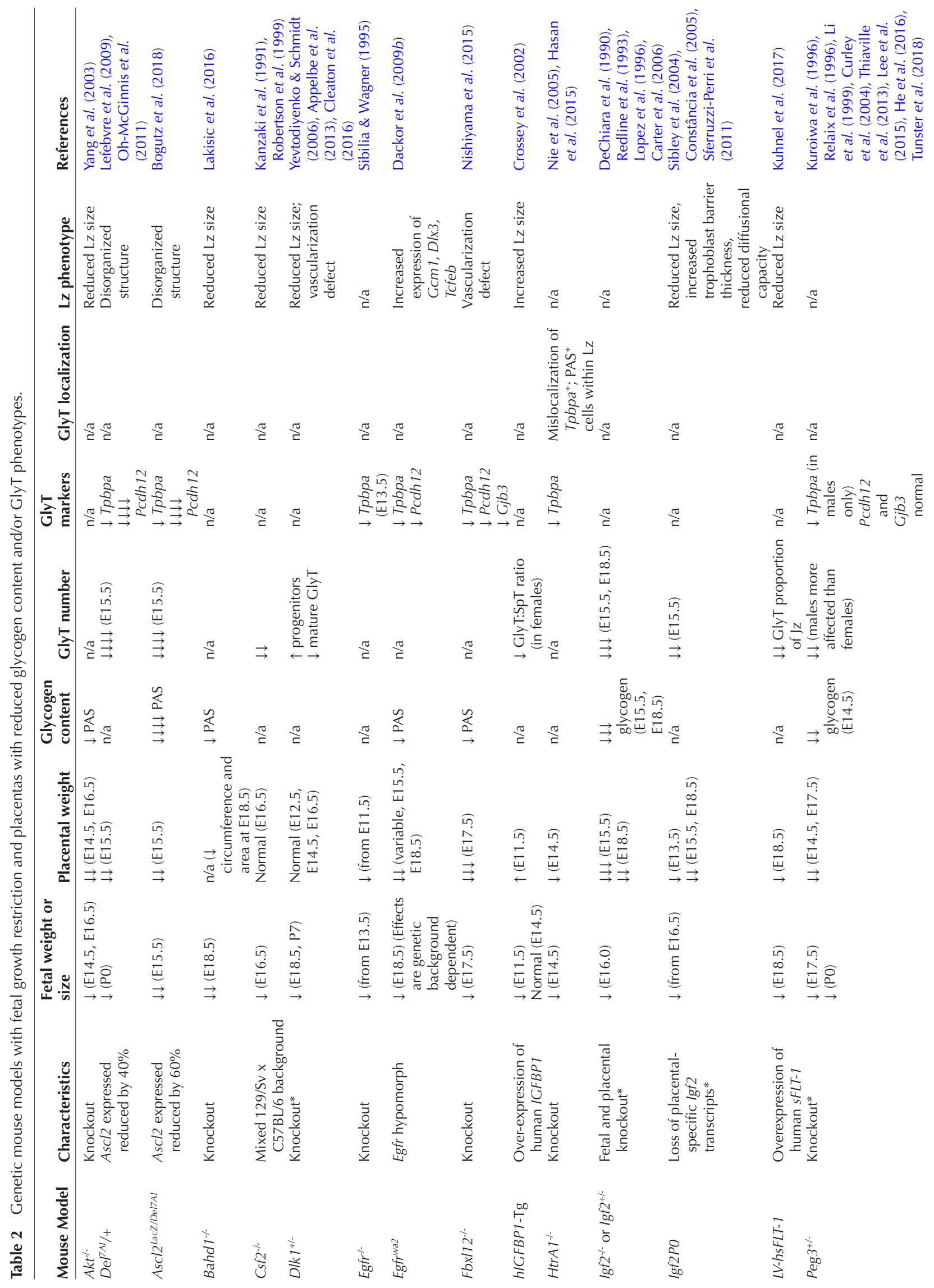




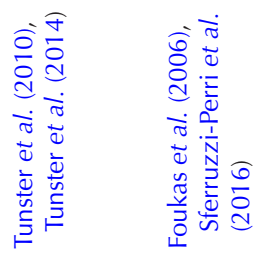
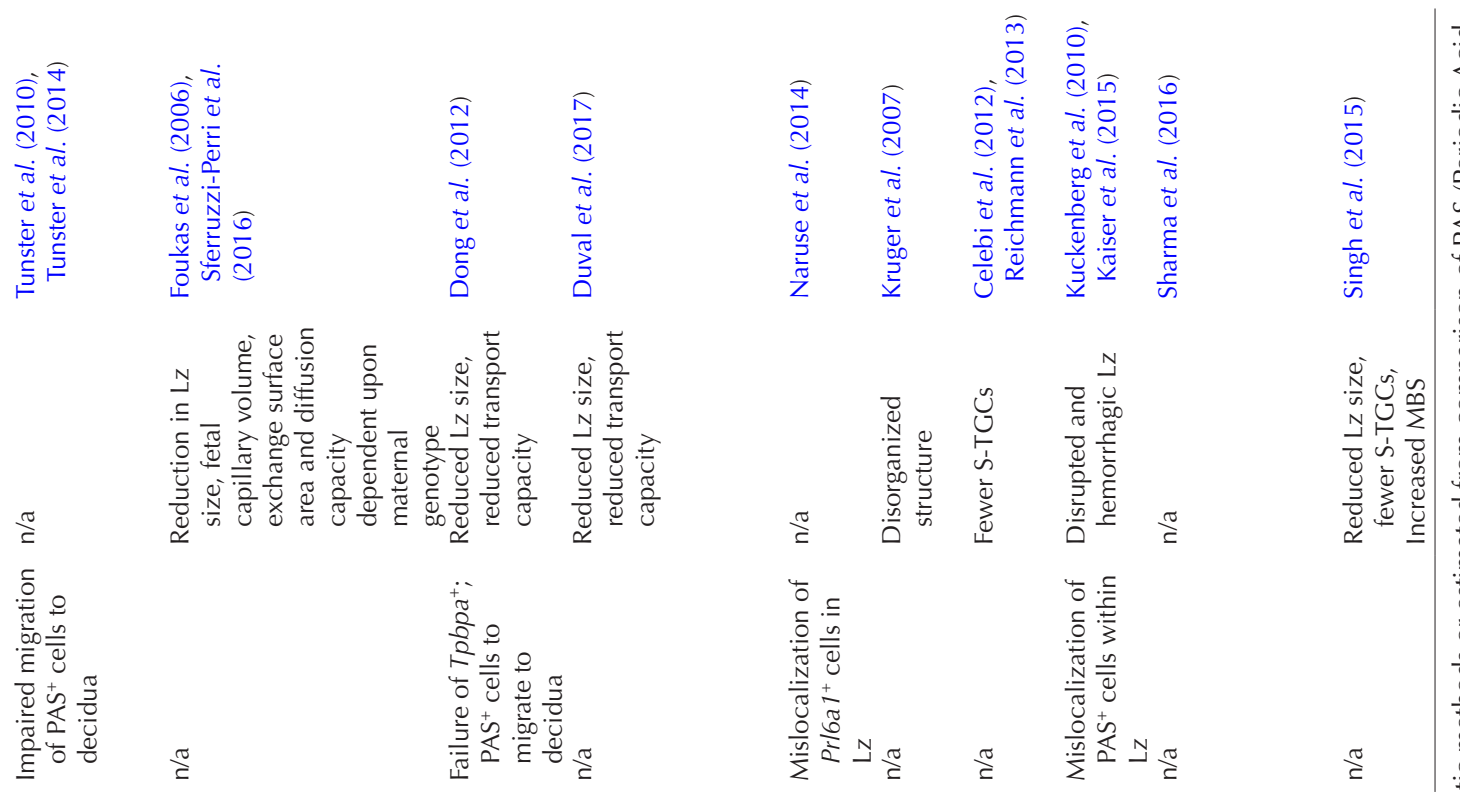

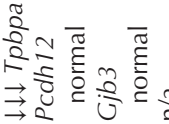

$\underset{\substack{\pi \\ \frac{0}{2}}}{\stackrel{2}{\frac{\delta}{2}}}$

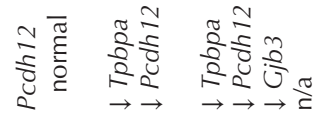

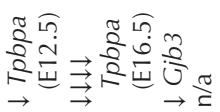
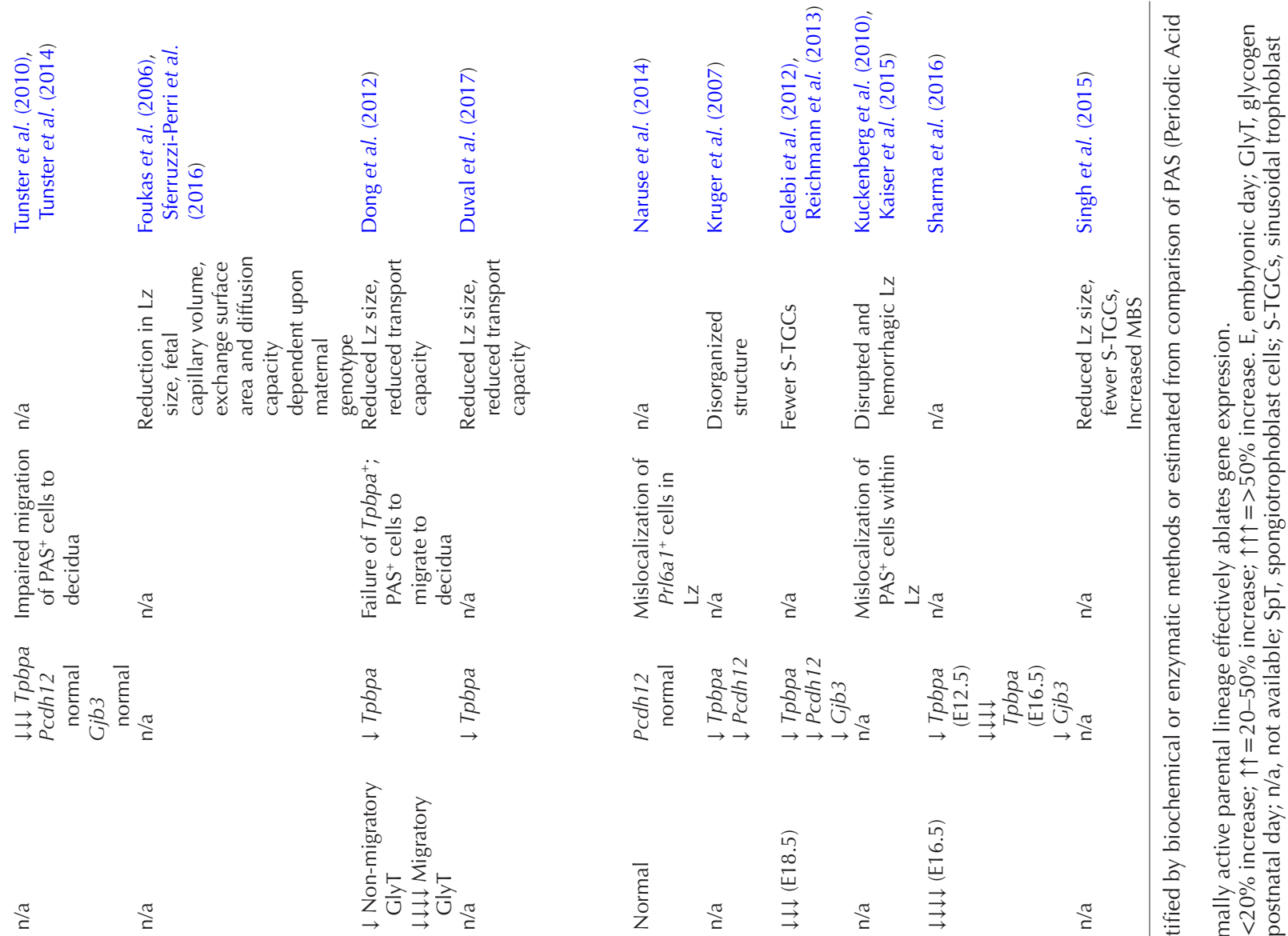

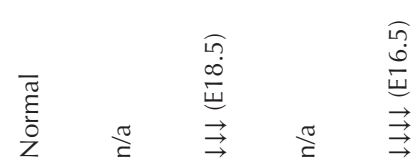

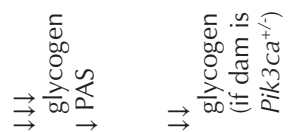

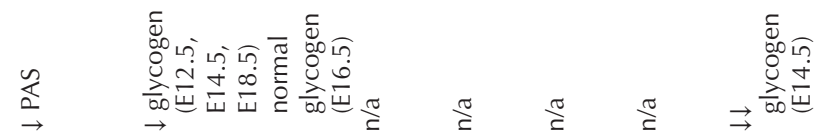

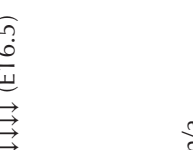

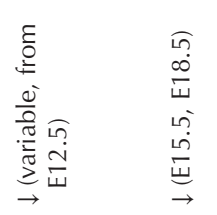

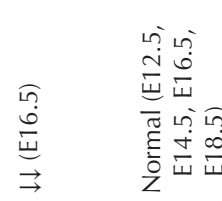

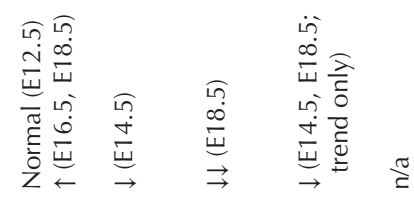

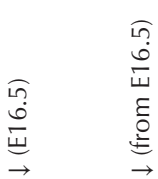

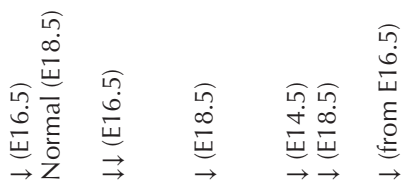

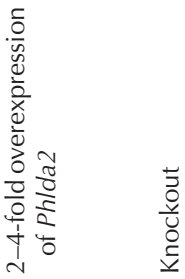

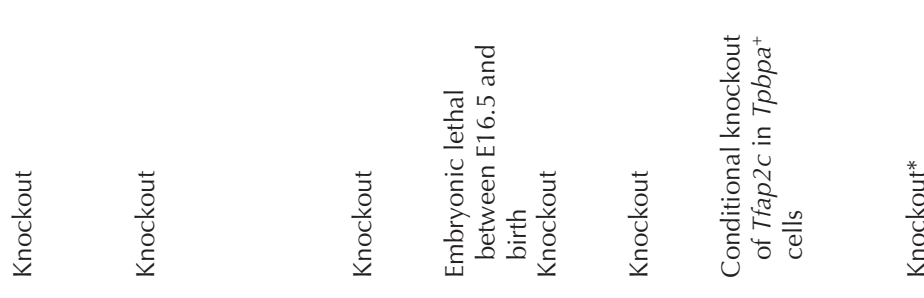

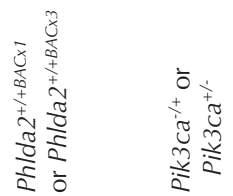

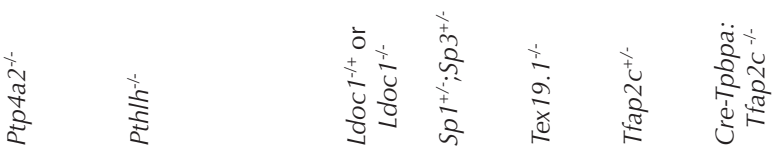
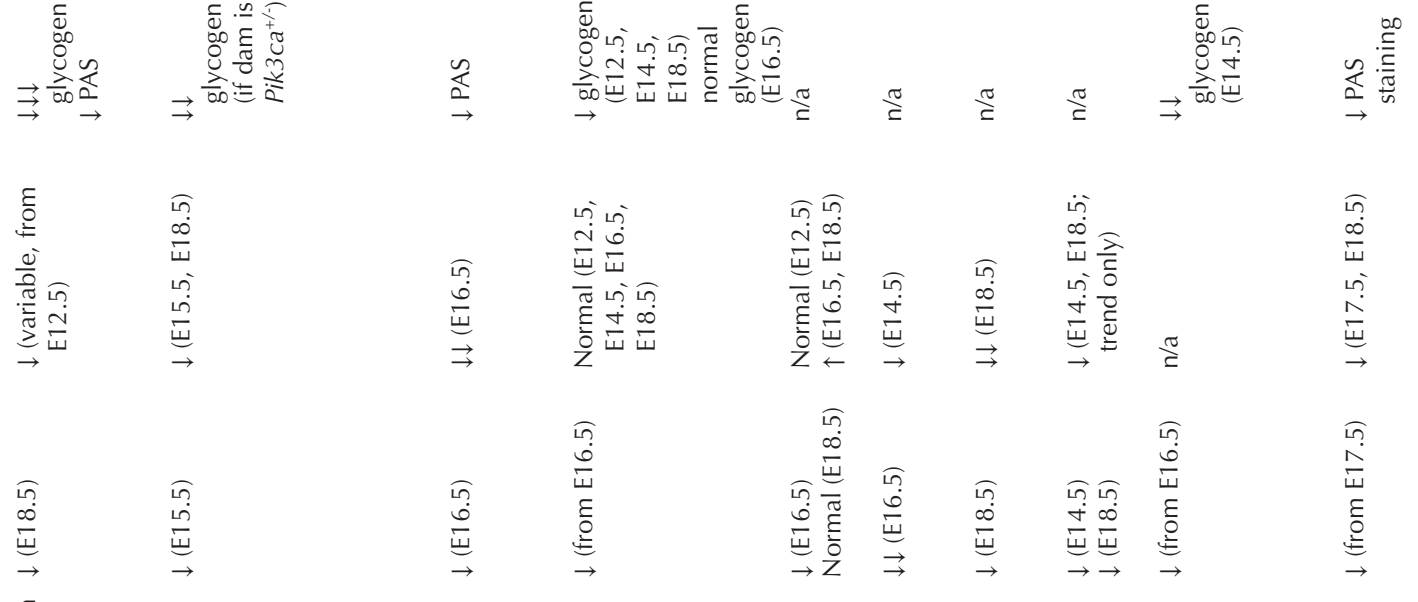


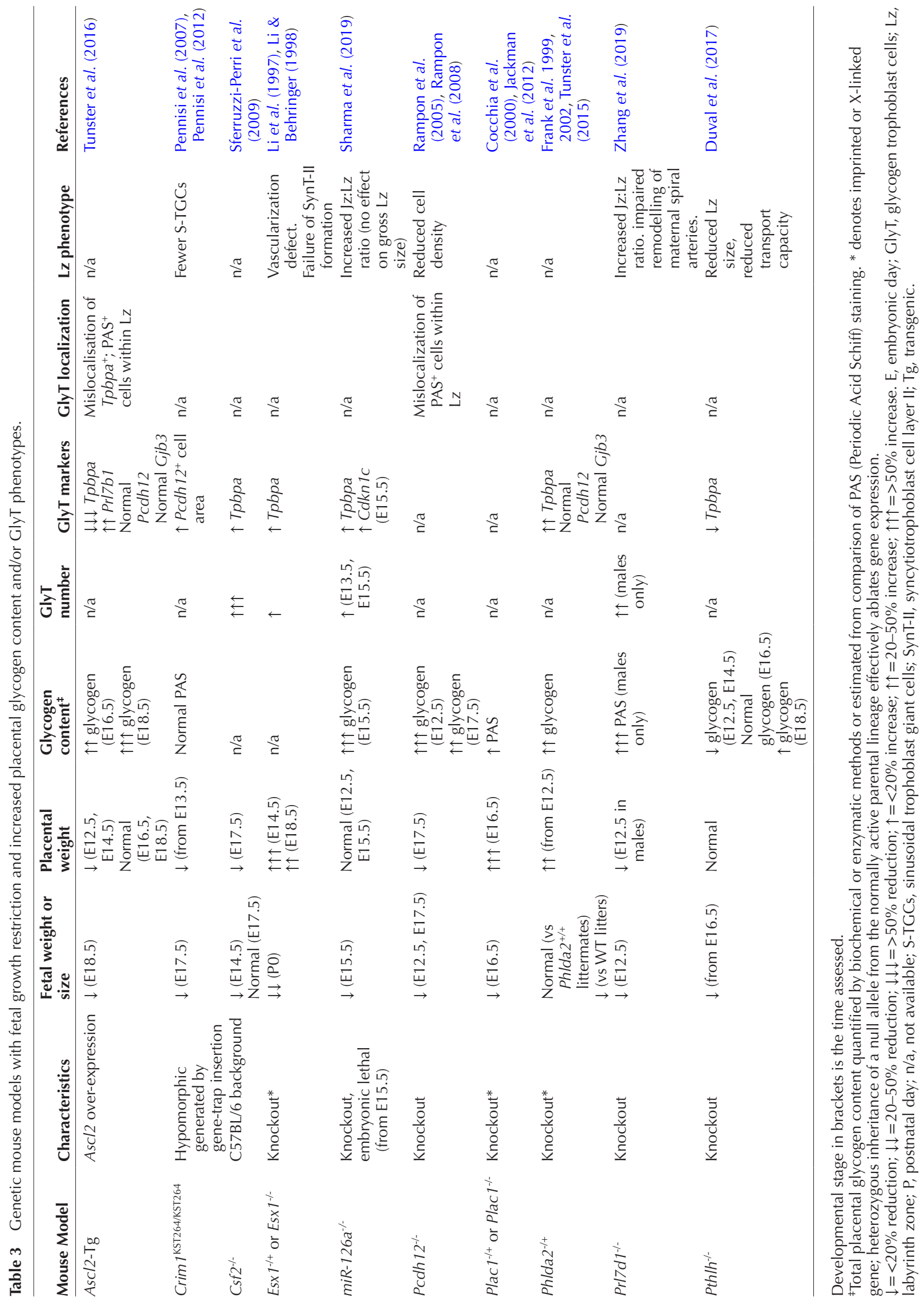




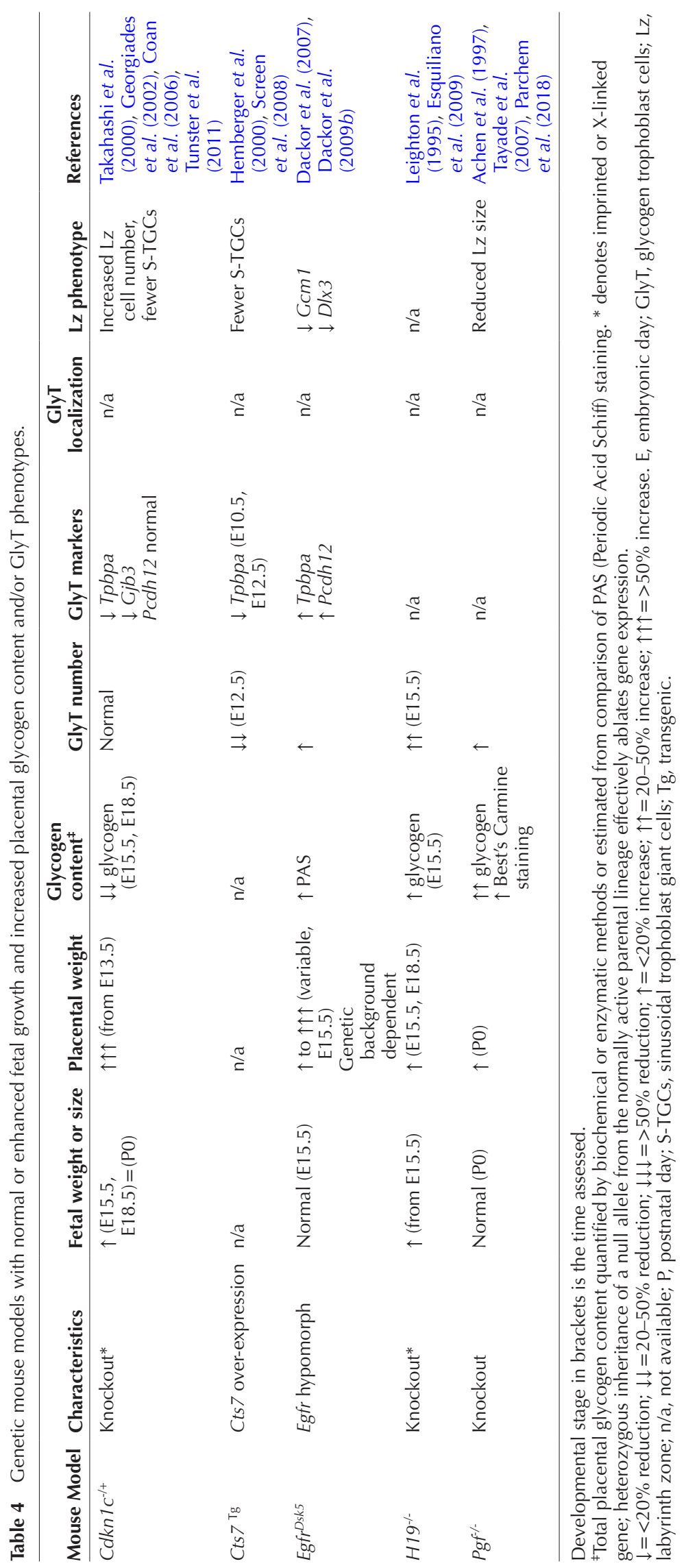




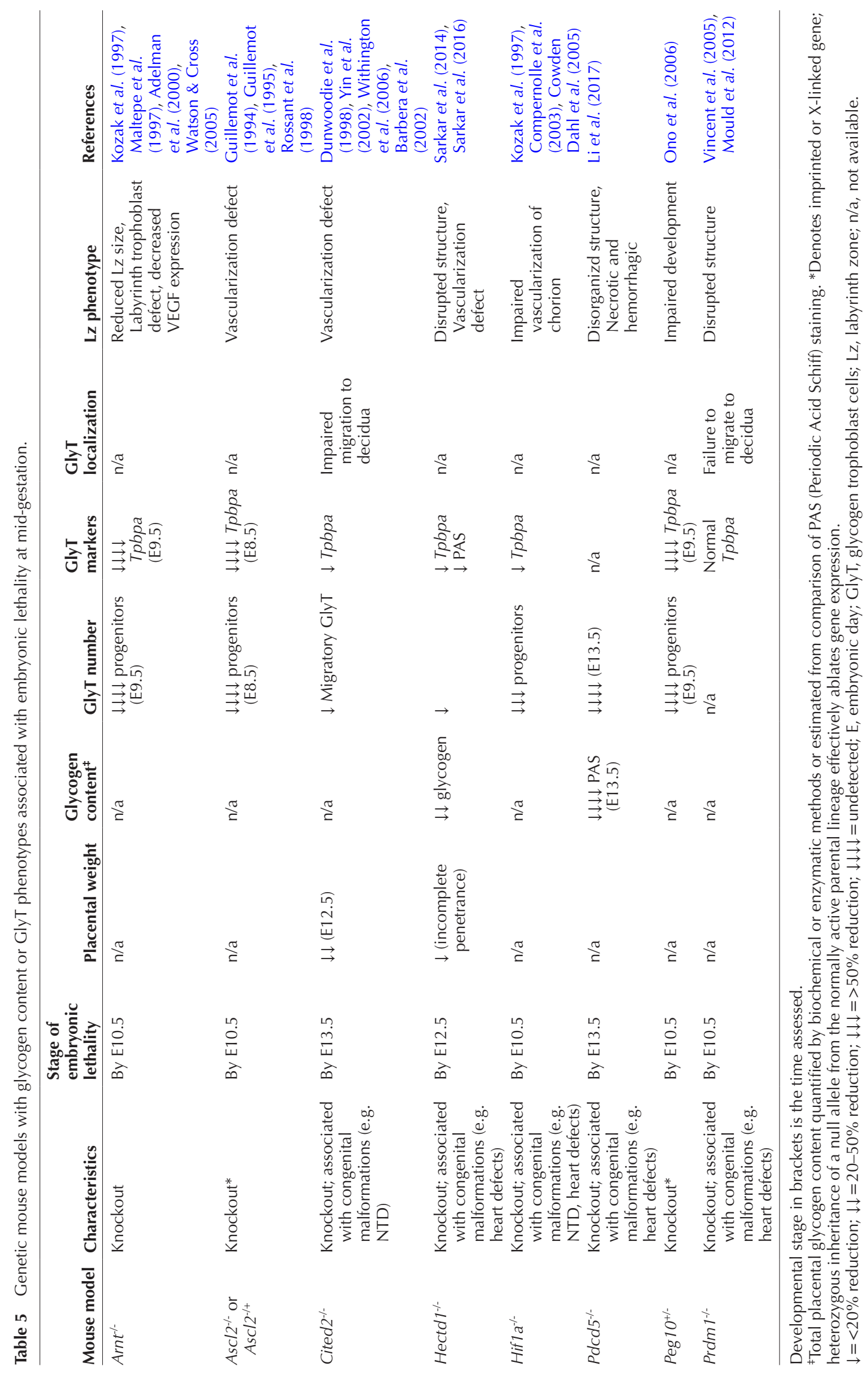


lethality at mid-gestation (Guillemot et al. 1994). Therefore, Ascl 2 is likely required for the formation of GlyT cells and might also be associated with glycogen storage or metabolism.

Beyond GlyT differentiation, several mouse strains demonstrate abnormal localization of GlyT (Table 2). Normally, GlyT are present in the Jz with a subpopulation of GlyT migrating into the decidua (Coan et al. 2006). Ldoc1, HtrA1 and Tfap2c single knockout mutations lead to placentas with GlyT that have mislocalized to the Lz (Naruse et al. 2014, Hasan et al. 2015, Kaiser et al. 2015). The Jz naturally interdigitates with the Lz (Soares \& Hunt 2014), the extent of which depends upon gestational stage and genetic background (Tunster et al. 2012). Therefore, it is important to be cautious when histologically characterizing the clusters of GlyT located in the Lz. Serial sections of placenta can be assessed to differentiate a GlyT cluster from a Jz finger protruding in to the Lz. Alternatively, failure of GlyT to migrate into the decidua, as in Ptp4a2 $2^{-/}$or Phlda2 overexpression mice (Tunster et al. 2010, Dong et al. 2012), might affect maternal-fetal interactions. Whether defective GlyT migration in these models results from altered cell-signalling pathways associated with adhesion and cytoskeleton or an inappropriate response to chemotactic signals remains to be determined. However, appropriate localization of GlyT appears to be important for normal fetal growth.

\section{Increased placental glycogen storage is also associated with impaired fetal growth}

Unexpectedly, FGR can also occur in the context of increased placental glycogen storage. For example, when the number of GlyT cells exceeded $35 \%$ of the $J z$, as in interspecific mouse hybrids, fetal growth was inversely correlated with GlyT abundance (Kurz et al. 1999). Additionally, several genetic mouse lines exist that demonstrate increased placental glycogen storage associated with FGR (Table 3). One potential explanation for these counterintuitive findings is that the mutant placentas are able to store glycogen but cannot effectively mobilize and release the glycogen. Further work is necessary to elucidate the mechanism, with a specific focus on whether glycogenesis is increased, leading to enhanced glycogen storage, whether glycogenolysis is impaired, leading to failed glucose release, or whether transport mechanisms are defective. Alternatively, FGR in models associated with increased placental glycogen storage might be caused by a mechanism independent of the GlyT or placental glycogen. Of note, some models (e.g. Ascl2-Tg, Pcdh $12^{-}$ - and Plac $1^{--}$) with increased glycogen storage also display mislocalization of GlyT clusters within the Lz (Rampon et al. 2008, Jackman et al. 2012, Tunster et al. 2016). This result is consistent with a role for the normal microenvironment of the $\mathrm{Jz}$ in modulating the mobilization of glycogen stores by the GlyT.

\section{Enhanced fetal growth might be independent of a GlyT phenotype}

It is possible for enhanced fetal growth to associate with aberrant placental glycogen storage, as occurs in $\mathrm{Cdkn}_{1} \mathrm{C}^{-/+}$and $\mathrm{H}^{-/-}$mice (Esquiliano et al. 2009, Tunster et al. 2011) (Table 4). However, it is unlikely that these placental phenotypes directly cause fetal overgrowth, since these genes exert an intrinsic effect on fetal growth. For instance, conditional overexpression of Cdkn1C in a subset of fetal, but not placental, tissues restricts fetal growth (John et al. 2001, Andrews et al. 2007). In contrast, while Cdkn1c knockout mice exhibit fetal overgrowth and placentomegaly at E15.5 and E18.5, fetal weights are normalized at birth (Tunster et al. 2011). This failure to sustain fetal overgrowth may be attributable to the manifestation of severe defects in $\mathrm{Cd} k n 1 \mathrm{C}^{-/+}$placentas including substantially diminished glycogen stores (Tunster et al. 2011), although GlyT abundance is unaffected (Takahashi et al. 2000). Similarly, ablation of $H 19$ drives overexpression of the growth-promoting gene lgf2, resulting in neonates that are $30 \%$ heavier than their littermates (Leighton et al. 1995), and placentas with increased GlyT number and placental glycogen content (Esquiliano et al. 2009). However, since the H19-driven fetal overgrowth phenotype persists to adulthood, the cause is likely independent of increased placental glycogen stores.

\section{GlyT phenotypes associated with early embryonic lethality}

Several genetic mouse models display a GlyT phenotype and result in embryonic lethality at or around midgestation (Table 5). This outcome occurs before GlyT cells mature and begin accumulating glycogen stores in earnest. Early fetal demise prevents a meaningful assessment of the effect of placental glycogen stores on fetal growth in this context. It is clear that embryonic lethality is attributable to a placental defect in the case of Ascl2 and Peg 10 knockouts, since lethality was rescued using a tetraploid aggregation approach (Guillemot et al. 1994, 1995, Ono et al. 2006). This method generates a chimeric conceptus in which a mutant fetus is supported by a placenta containing WT tetraploid cells (Tarkowski et al. 1977, Nagy et al. 1990). In this context, rescue of embryonic lethality indicates a placental cause. Embryonic lethality in the remaining models coincides with the appearance of congenital malformations (Table 5). A conditional knockout approach is required to elucidate the role of these genes in later stage placentas, including in GlyT development and function. A recent study demonstrated that defects in placental 
development and/or function might contribute to the formation of congenital malformations in the fetus, particularly those affecting heart, brain and vascular development (Perez-Garcia et al. 2018). The extent to which GlyT and placental glycogen stores play a role in this phenomenon is yet to be determined.

\section{Limitations}

While the studies presented here broadly support a role for placental glycogen in regulating fetal growth, a major limitation to understanding the true causeeffect relationship is that the Lz structure is also disrupted in many of these models (Tables 2, 3, 4 and 5). The Lz facilitates the exchange of nutrients, gases and waste products between maternal and fetal circulations (Watson \& Cross 2005). Reduced branching morphogenesis in the Lz decreases the surface area for nutrient transport, compromising placental function (Cross et al. 2006). Consequently, it is difficult to directly attribute the adverse fetal growth outcomes specifically to aberrant placental glycogen storage for most genes. One model in which fetal growth and placental glycogen content might show a direct link is the Egfr hypomorph mutation. These mutant mice have placentas with a GlyT-specific phenotype characterized by reduced PAS staining and diminished GlyT-marker expression but no other placental defect. Associated fetuses were growth restricted in a background-specific manner, with Egfr hypomorphs growth restricted on the 129Sv and BTBR/J backgrounds but not the C57BL/6J background (Dackor et al. 2009a). Crucially, while PAS staining of Egfr hypomorphic placentas was reduced on the 129Sv and BTBR/J backgrounds, abundant PAS staining was evident on the C57BL/6 genetic background (Dackor et al. 2009b). This emphasizes a potential relationship between glycogen storage and fetal growth.

The ability to ascertain the mechanism driving aberrant glycogen storage from existing studies is difficult given that GlyT abundance and total placental glycogen content are not always assessed together. Therefore, it is unclear whether an early defect in GlyT progenitor maintenance or differentiation leading to a reduction in mature GlyT cells is the main cause of glycogen storage defects. This appears to be the case for at least 11 mutant mouse lines where both parameters have been assessed (Table 1). The majority of studies have assessed only a single parameter: GlyT abundance or placental glycogen content. This will affect the conclusions drawn by each study and not necessarily reflect whether the mechanism is developmental or metabolic in origin. The only known model whereby placental glycogen stores are independent of GlyT differentiation and abundance is the Cdkn1c null line (Tunster et al. 2011, Takahashi et al. 2000). From this model, we might better understand how glycogen metabolism occurs in the placenta and how fetal growth responds.

\section{Future directions}

Considerable work is required to fully elucidate the normal physiological role of placental glycogen stores in humans given that we are only beginning to understand its role during pregnancy. To improve our understanding, a systematic analysis of the GlyT population is required in known mouse models with placenta phenotypes and as part of the routine assessment of new mouse placenta phenotypes. We have proposed four key parameters to assess the GlyT lineage to better understand their development and function: (1.) quantification of GlyT cell number as determined by nuclear counts on histological sections; (2.) assessment of GlyT-specific marker gene expression (e.g. Pcdh12, Aldh1a3 and Gjb3) either by in situ hybridization on histological sections (Fig. 2) or by qPCR analysis at multiple stages of development. This should occur in concert with assessment of other trophoblast lineage marker expression; (3.) analysis of the localization of GlyT cells by undergoing in situ hybridization for the migratory (Pr/7b1) and nonmigratory (Prl6a1) markers. This will indicate the migratory capacity of these cells and whether placental structure is affected and (4.) exploring placental glycogen content by performing PAS staining of histological sections (Fig. 2) alongside quantification of total placental glycogen content using a biochemical assay (Lo et al. 1970). Altogether, these criteria will help to direct subsequent phenotype evaluation and ultimately identify further molecules and pathways important for GlyT formation and function and for the regulation of placental glycogen stores.

Given the highly dynamic nature of the GlyT cells over the course of pregnancy, it is important to assess placental glycogen-related phenotypes (and arguably other placental phenotypes) at multiple gestational stages. Characterization of a single developmental stage might misrepresent the full extent of the phenotype. One model that exemplifies this issue is the Pthlh knockout mouse (Duval et al. 2017), whereby placental glycogen content was reduced at E12.5 and E14.5. By E16.5, glycogen had normalized to control levels. However, glycogen content was elevated at E18.5 relative to controls, failing to exhibit the anticipated decline toward term that is normally attributed to the mobilisation of glycogen stores in late gestation. Coinciding with the glycogen phenotype, fetal growth was restricted from E16.5 (Duval et al. 2017). Although Pthlh-null mice exhibit severe skeletal abnormalities and die soon after birth (Karaplis et al. 1994, Bond et al. 2008), the lateonset FGR observed in this model implicates a causal role for placental dysfunction. However, it is unclear whether FGR can be attributed to impaired glycogen storage during mid-gestation or the apparent failure to mobilize placental glycogen stores at term. Assessing phenotypes at multiple stages of development will 
potentially allow for better separation of developmental defects from functional defects.

The regulation of glycogenesis and glycogenolysis pathway activity by GlyT will provide further insight into placental glycogen metabolism. Central to glucose release from a cell is the enzyme glucose 6-phosphatase, which is responsible for generating free glucose by hydrolyzing the polar phosphate group from glucose 6-phosphate and allowing its transport out of the cell (van Schaftingen \& Gerin 2002). The absence of glucose 6-phosphatase activity in GlyT cells would prevent the release of glucose for consumption by the fetus, mother or trophoblast cells. While expression of glucose 6-phosphatase has not been investigated in the mouse placenta to date, its activity in the human placenta is attributed to the G6PC3 isoform (Guionie et al. 2003). This isoform is distinct from the liver-specific G6PC1 isoform and is expressed in the placenta from at least week 28 of human pregnancy (Matsubara et al. 1999) and may be associated with the production of glucose in the placenta at term (Prendergast et al. 1999). However, the ultimate destination of glucose derived from placental glycogen stores remains unclear. It is possible that it is directed for fetal use and/or placental consumption. Signals from the fetus that release placental glycogen stores have not been identified.

It is also possible that placental glycogen stores support maternal physiology. The localization of nonmigratory GlyT around channels that drain maternal blood from the placenta suggests that some of the glucose released from placental glycogen stores may first be available for uptake by the mother. GlyT express several $\mathrm{Prl}$ genes and the localization of non-migratory GlyT suggest the encoded hormones may be released into maternal blood. While placental hormones are known to adapt maternal physiology to pregnancy, there is currently no evidence that the glucose metabolized from placental glycogen stores acts to the benefit of maternal physiology. Future studies should assess the effects of aberrant placental glycogen storage on maternal physiology. Indeed, genetic perturbations of several genes that regulate the GlyT lineage also have effects on maternal behavior, including Peg3 (Li et al. 1999, McNamara et al. 2018) and Phlda2 (Creeth et al. 2018). Little is known about changes to maternal physiology in these models. DIk $1^{+-}$mice are the only model in which maternal physiology was characterized in association with a placental GlyT phenotype (Appelbe et al. 2013, Cleaton et al. 2016). However, the effects on maternal physiology are more likely attributable to the loss of circulating DLK1 (also known as fetal antigen-1; FA1), rather than a consequence of altered placental glycogen metabolism.

Conversely, there is evidence that maternal physiology can regulate placental glycogen stores. A loss-of-function allele of Pik3ca, which encodes for the catalytic subunit of phosphatidylinositol 3-kinase (PI3K), showed a maternal zygotic effect resulting in diminished glycogen stores (Sferruzzi-Perri et al. 2016), although the underlying mechanism is not well understood. While manipulation of maternal diet modulates fetal growth in mouse models (Zhang et al. 2005, 2009, Jones et al. 2009), only a few studies have investigated the effect of maternal diet upon placental glycogen storage. Both calorie and protein restriction in dams impair placental glycogen storage (Coan et al. 2010, SferruzziPerri et al. 2011, Gonzalez et al. 2016), presumably as a consequence of diminished nutrient availability. A high sugar, high fat (HSHF) maternal diet results in FGR at E15.5, a phenotype that is normalized by E18.5 (Sferruzzi-Perri et al. 2013), potentially due to increased utilization of glycogen to support accelerated fetal growth during late gestation. Further work is necessary to explore the relationship between maternal diet, placental glycogen metabolism and fetal growth.

Attempts to infer the function of placental glycogen in models where the GlyT lineage is ablated or diminished might be confounded by additional functions of GlyT cells, which perform at least two additional functions to glycogen storage. First, GlyT cells contribute to placental endocrine function as evidenced by their expression of a subset of the Prl gene cluster (Simmons et al. 2008b). Secondly, GlyT expression of ALDH1A3, an enzyme that oxidises retinal to retinoic acid, implies that GlyT might be a source of retinoic acid, which is an important regulator of trophoblast differentiation (Outhwaite et al. 2015). Therefore, alterations in the GlyT population might have profound effects on placental structure and function independent of glycogen storage.

Overall, better characterization of GlyT phenotypes in mice will allow us to evaluate the glycogenesis and glycogenolysis pathways involved in storing and metabolizing glycogen in normal pregnancies and pathological contexts. More sophisticated approaches to constitutive gene knockout models will be necessary to elucidate the specific physiological role(s) of placental glycogen. These analyses should include single-cell sequencing approaches to better understand genetic and metabolic pathways within GlyT cells together with a more holistic approach that relates placental structure and glycogen metabolism to fetal growth and development and to maternal physiology. Only then will the normal function and relevance of aberrant placental glycogen stores to human pregnancy complications, such as PE and GDM, be clarified.

\section{Declaration of interest}

The authors declare that there is no conflict of interest that could be perceived as prejudicing the impartiality of this review. 


\section{Funding}

S J T was funded by a Centre for Trophoblast Research Next Generation Fellowship.

\section{Author contribution statement}

S J T conceived the study. S J T, E D W, A L F and G J B wrote and edited the manuscript. All authors have read and approved the final version of this manuscript.

\section{References}

Achen MG, Gad JM, Stacker SA \& Wilks AF 1997 Placenta growth factor and vascular endothelial growth factor are co-expressed during early embryonic development. Growth Factors 15 69-80. (https://doi. org/10.3109/08977199709002113)

Adamson SL, Lu Y, Whiteley KJ, Holmyard D, Hemberger M, Pfarrer C \& Cross JC 2002 Interactions between trophoblast cells and the maternal and fetal circulation in the mouse placenta. Developmental Biology 250 358-373. (https://doi.org/10.1016/s0012-1606(02)90773-6)

Adelman DM, Gertsenstein M, Nagy A, Simon MC \& Maltepe E 2000 Placental cell fates are regulated in vivo by HIF-mediated hypoxia responses. Genes and Development 14 3191-3203. (https://doi. org/10.1101/gad.853700)

Akison LK, Nitert MD, Clifton VL, Moritz KM \& simmons DG 2017 Review: Alterations in placental glycogen deposition in complicated pregnancies: current preclinical and clinical evidence. Placenta 54 52-58. (https://doi.org/10.1016/j.placenta.2017.01.114)

Andrews SC, Wood MD, Tunster SJ, Barton SC, Surani MA \& John RM 2007 Cdkn1c (p57Kip2) is the major regulator of embryonic growth within its imprinted domain on mouse distal chromosome 7. BMC Developmental Biology 7 53. (https://doi.org/10.1186/1471-213X-7-53)

Angiolini E, Fowden A, Coan P, Sandovici I, Smith P, Dean W, Burton G, Tycko B, Reik W, Sibley C et al. 2006 Regulation of placental efficiency for nutrient transport by imprinted genes. Placenta 27 (Supplement A) S98-102. (https://doi.org/10.1016/j.placenta.2005.12.008)

Appelbe OK, Yevtodiyenko A, Muniz-Talavera H \& Schmidt JV 2013 Conditional deletions refine the embryonic requirement for Dlk1. Mechanisms of Development 130 143-159. (https://doi.org/10.1016/j. $\bmod .2012 .09 .010)$

Arkwright PD, Rademacher TW, Dwek RA \& Redman CW 1993 Preeclampsia is associated with an increase in trophoblast glycogen content and glycogen synthase activity, similar to that found in hydatidiform moles. Journal of Clinical Investigation 91 2744-2753. (https://doi. org/10.1172/JCl116515)

Baker J, Liu JP, Robertson EJ \& Efstratiadis A 1993 Role of insulin-like growth factors in embryonic and postnatal growth. Cell 75 73-82. (https://doi.org/10.1016/S0092-8674(05)80085-6)

Baladron V, Ruiz-Hidalgo MJ, Nueda ML, Diaz-Guerra MJ, GarciaRamirez JJ, Bonvini E, Gubina E \& Laborda J 2005 dlk acts as a negative regulator of Notch1 activation through interactions with specific EGFlike repeats. Experimental Cell Research 303 343-359. (https://doi. org/10.1016/j.yexcr.2004.10.001)

Barash V \& Shafrir E 1990 Mobilization of placental glycogen in diabetic rats. Placenta 11 515-521. (https://doi.org/10.1016/s01434004(05)80197-3)

Barbera JP, Rodriguez TA, Greene ND, Weninger WJ, Simeone A, Copp AJ, Beddington RS \& Dunwoodie S 2002 Folic acid prevents exencephaly in Cited2 deficient mice. Human Molecular Genetics 11 283-293. (https:// doi.org/10.1093/hmg/11.3.283)

Bierne H, Tham TN, Batsche E, Dumay A, Leguillou M, KerneisGolsteyn S, Regnault B, Seeler JS, Muchardt C, Feunteun J et al. 2009 Human BAHD1 promotes heterochromatic gene silencing. PNAS 106 13826-13831. (https://doi.org/10.1073/pnas.0901259106)

Bogutz AB, Oh-Mcginnis R, Jacob KJ, Ho-Lau R, Gu T, Gertsenstein M, Nagy A \& Lefebvre L 2018 Transcription factor ASCL2 is required for development of the glycogen trophoblast cell lineage. PLoS Genetics $\mathbf{1 4}$ e1007587. (https://doi.org/10.1371/journal.pgen.1007587)
Bond H, Dilworth MR, Baker B, Cowley E, Jimenez AR, Boyd RDH, Husain SM, Ward BS, Sibley CP \& Glazier JD 2008 Increased maternofetal calcium flux in parathyroid hormone-related protein-null mice. Journal of Physiology 586 2015-2025. (https://doi.org/10.1113/ jphysiol.2007.149104)

Bouillot S, Rampon C, Tillet E \& Huber P 2006 Tracing the glycogen cells with protocadherin 12 during mouse placenta development. Placenta $\mathbf{2 7}$ 882-888. (https://doi.org/10.1016/j.placenta.2005.09.009)

Boyd J 1959 Glycogen in Early Human Implantation Sites.

Breier G, Clauss M \& Risau W 1995 Coordinate expression of vascular endothelial growth factor receptor-1 (flt-1) and its ligand suggests a paracrine regulation of murine vascular development. Developmental Dynamics 204 228-239. (https://doi.org/10.1002/aja.1002040303)

Burton GJ \& Fowden AL 2015 The placenta: a multifaceted, transient organ. Philosophical Transactions of the Royal Society of London: Series B, Biological Sciences 370 20140066. (https://doi.org/10.1098/ rstb.2014.0066)

Carter AM, Nygard K, Mazzuca DM \& Han VK 2006 The expression of insulin-like growth factor and insulin-like growth factor binding protein mRNAs in mouse placenta. Placenta 27 278-290. (https://doi. org/10.1016/j.placenta.2005.01.014)

Celebi C, Van Montfoort A, Skory V, Kieffer E, Kuntz S, Mark M \& Viville S 2012 Tex 19 paralogs exhibit a gonad and placenta-specific expression in the mouse. Journal of Reproduction and Development 58 360-365. (https://doi.org/10.1262/jrd.11-047k)

Cleaton MA, Dent CL, Howard M, Corish JA, Gutteridge I, Sovio U, Gaccioli F, Takahashi N, Bauer SR, Charnock-Jones DS et al. 2016 Fetus-derived DLK1 is required for maternal metabolic adaptations to pregnancy and is associated with fetal growth restriction. Nature Genetics 48 1473-1480. (https://doi.org/10.1038/ng.3699)

Coan PM, Conroy N, Burton GJ \& Ferguson-Smith AC 2006 Origin and characteristics of glycogen cells in the developing murine placenta. Developmental Dynamics 235 3280-3294. (https://doi.org/10.1002/ dvdy.20981)

Coan PM, Vaughan OR, Sekita Y, Finn SL, Burton GJ, Constancia M \& Fowden AL 2010 Adaptations in placental phenotype support fetal growth during undernutrition of pregnant mice. Journal of Physiology 588 527-538. (https://doi.org/10.1113/jphysiol.2009.181214)

Cocchia M, Huber R, Pantano S, Chen EY, Ma P, Forabosco A, Ko MS \& Schlessinger D 2000 PLAC1, an Xq26 gene with placentaspecific expression. Genomics 68 305-312. (https://doi.org/10.1006/ geno.2000.6302)

Compernolle V, Brusselmans K, Franco D, Moorman A, Dewerchin M, Collen D \& Carmeliet P 2003 Cardia bifida, defective heart development and abnormal neural crest migration in embryos lacking hypoxiainducible factor-1alpha. Cardiovascular Research 60 569-579. (https:// doi.org/10.1016/j.cardiores.2003.07.003)

Constância M, Angiolini E, Sandovici I, Smith P, Smith R, Kelsey G, Dean W, Ferguson-Smith A, Sibley CP, Reik W et al. 2005 Adaptation of nutrient supply to fetal demand in the mouse involves interaction between the Igf2 gene and placental transporter systems. PNAS $\mathbf{1 0 2}$ 19219-19224. (https://doi.org/10.1073/pnas.0504468103)

Cowden Dahl KD, Fryer BH, Mack FA, Compernolle V, Maltepe E, Adelman DM, Carmeliet P \& Simon MC 2005 Hypoxia-inducible factors 1 alpha and 2alpha regulate trophoblast differentiation. Molecular and Cellular Biology 25 10479-10491. (https://doi.org/10.1128/ MCB.25.23.10479-10491.2005)

Creeth HDJ, Mcnamara GI, Tunster SJ, Boque-Sastre R, Allen B, Sumption L, Eddy JB, Isles AR \& John RM 2018 Maternal care boosted by paternal imprinting in mammals. PLoS Biology 16 e2006599. (https:// doi.org/10.1371/journal.pbio.2006599)

Cross DA, Alessi DR, Cohen P, Andjelkovich M \& Hemmings BA 1995 Inhibition of glycogen synthase kinase- 3 by insulin mediated by protein kinase B. Nature 378 785-789. (https://doi.org/10.1038/378785a0)

Cross JC, Nakano H, Natale DR, Simmons DG \& Watson ED 2006 Branching morphogenesis during development of placental villi. Differentiation: Research in Biological Diversity 74 393-401. (https://doi. org/10.1111/j.1432-0436.2006.00103.x)

Crossey PA, Pillai CC \& Miell JP 2002 Altered placental development and intrauterine growth restriction in IGF binding protein-1 transgenic mice. Journal of Clinical Investigation 110 411-418. (https://doi.org/10.1172/ $\mathrm{JCl} 10077)$ 
Curley JP, Barton S, Surani A \& Keverne EB 2004 Coadaptation in mother and infant regulated by a paternally expressed imprinted gene. Proceedings: Biological Sciences 271 1303-1309. (https://doi. org/10.1098/rspb.2004.2725)

Dackor J, Strunk KE, Wehmeyer MM \& Threadgill DW 2007 Altered trophoblast proliferation is insufficient to account for placental dysfunction in egfr null embryos. Placenta 28 1211-1218. (https://doi. org/10.1016/j.placenta.2007.07.005)

Dackor J, Caron KM \& Threadgill DW 2009a Placental and embryonic growth restriction in mice with reduced function epidermal growth factor receptor alleles. Genetics 183 207-218. (https://doi.org/10.1534/ genetics.109.104372)

Dackor J, Li M \& Threadgill DW 2009b Placental overgrowth and fertility defects in mice with a hypermorphic allele of epidermal growth factor receptor. Mammalian Genome 20 339-349. (https://doi.org/10.1007/ s00335-009-9189-2)

Dechiara TM, Efstratiadis A \& Robertson EJ 1990 A growth-deficiency phenotype in heterozygous mice carrying an insulin-like growth factor II gene disrupted by targeting. Nature 345 78-80. (https://doi. org/10.1038/345078a0)

Desoye G, Hofmann HH \& Weiss PA 1992 Insulin binding to trophoblast plasma membranes and placental glycogen content in well-controlled gestational diabetic women treated with diet or insulin, in well-controlled overt diabetic patients and in healthy control subjects. Diabetologia 35 45-55. (https://doi.org/10.1007/bf00400851)

Desoye G, Korgun ET, Ghaffari-Tabrizi N \& Hahn T 2002 Is fetal macrosomia in adequately controlled diabetic women the result of a placental defect? A hypothesis. Journal of Maternal-Fetal and Neonatal Medicine 11 258-261. (https://doi.org/10.1080/jmf.11.4.258.261)

Deussing J, Kouadio M, Rehman S, Werber I, Schwinde A \& Peters C 2002 Identification and characterization of a dense cluster of placenta-specific cysteine peptidase genes and related genes on mouse chromosome 13. Genomics 79 225-240. (https://doi.org/10.1006/geno.2002.6696)

Diamant YZ, Metzger BE, Freinkel N \& Shafrir E 1982 Placental lipid and glycogen content in human and experimental diabetes mellitus. American Journal of Obstetrics and Gynecology 144 5-11. (https://doi. org/10.1016/0002-9378(82)90385-4)

Diehl JA, Cheng M, Roussel MF \& Sherr CJ 1998 Glycogen synthase kinase3beta regulates cyclin D1 proteolysis and subcellular localization. Genes and Development 12 3499-3511. (https://doi.org/10.1101/ gad.12.22.3499)

Dong Y, Zhang L, Zhang S, Bai Y, Chen H, Sun X, Yong W, Li W, Colvin SC, Rhodes SJ et al. 2012 Phosphatase of regenerating liver 2 (PRL2) is essential for placental development by down-regulating PTEN (phosphatase and tensin homologue deleted on chromosome 10) and activating Akt protein. Journal of Biological Chemistry 287 32172-32179. (https://doi.org/10.1074/jbc.M112.393462)

Driessen LF 1907 Ueber glykogen in der placenta. Archiv für Gynaekologie 82 278-301. (https://doi.org/10.1007/BF01785087)

Dunwoodie SL, Rodriguez TA \& Beddington RS 1998 Msg1 and Mrg1, founding members of a gene family, show distinct patterns of gene expression during mouse embryogenesis. Mechanisms of Development 72 27-40. (https://doi.org/10.1016/s0925-4773(98)00011-2)

Duval C, Dilworth MR, Tunster SJ, Kimber SJ \& Glazier JD 2017 PTHrP is essential for normal morphogenetic and functional development of the murine placenta. Developmental Biology 430 325-336. (https://doi. org/10.1016/j.ydbio.2017.08.033)

Efstratiadis A 1998 Genetics of mouse growth. International Journal of Developmental Biology 42 955-976.

Esquiliano DR, Guo W, Liang L, Dikkes P \& Lopez MF 2009 Placental glycogen stores are increased in mice with $\mathrm{H} 19$ null mutations but not in those with insulin or IGF type 1 receptor mutations. Placenta 30 693-699. (https://doi.org/10.1016/j.placenta.2009.05.004)

Forbes K \& Westwood M 2008 The IGF axis and placental function. a mini review. Hormone Research 69 129-137. (https://doi. org/10.1159/000112585)

Foukas LC, Claret M, Pearce W, Okkenhaug K, Meek S, Peskett E, Sancho S, Smith AJ, Withers DJ \& Vanhaesebroeck B 2006 Critical role for the p110alpha phosphoinositide-3-OH kinase in growth and metabolic regulation. Nature 441 366-370. (https://doi.org/10.1038/nature04694)

Frank D, Mendelsohn CL, Ciccone E, Svensson K, Ohlsson R \& Tycko B 1999 A novel pleckstrin homology-related gene family defined by Ipl/
Tssc3, TDAG51, and Tih1: tissue-specific expression, chromosomal location, and parental imprinting. Mammalian Genome 10 1150-1159. (https://doi.org/10.1007/s003359901182)

Frank D, Fortino W, Clark L, Musalo R, Wang W, Saxena A, Li CM, Reik W, Ludwig T \& Tycko B 2002 Placental overgrowth in mice lacking the imprinted gene Ipl. PNAS 99 7490-7495. (https://doi.org/10.1073/ pnas.122039999)

Frost JM \& Moore GE 2010 The importance of imprinting in the human placenta. PLoS Genetics 6 e1001015. (https://doi.org/10.1371/journal. pgen.1001015)

Gabbe SG, Demers LM, Greep RO \& Villee CA 1972 Placental glycogen metabolism in diabetes mellitus. Diabetes 21 1185-1191. (https://doi. org/10.2337/diab.21.12.1185)

Gasperowicz M, Surmann-Schmitt C, Hamada Y, Otto F \& Cross JC 2013 The transcriptional co-repressor TLE3 regulates development of trophoblast giant cells lining maternal blood spaces in the mouse placenta. Developmental Biology 382 1-14. (https://doi.org/10.1016/j. ydbio.2013.08.005)

Georgiades P, Ferguson-Smith AC \& Burton GJ 2002 Comparative developmental anatomy of the murine and human definitive placentae. Placenta 23 3-19. (https://doi.org/10.1053/plac.2001.0738)

Gheorman V, Gheorman L, Ivanus C, Pana RC, Goganau AM \& Patrascu A 2013 Comparative study of placenta acute fetal distress and diabetes associated with pregnancy. Romanian Journal of Morphology and Embryology $\mathbf{5 4}$ 505-511.

Gonzalez PN, Gasperowicz M, Barbeito-Andres J, Klenin N, Cross JC \& Hallgrimsson B 2016 Chronic protein restriction in mice impacts placental function and maternal body weight before fetal growth. PLoS ONE 11 e0152227. (https://doi.org/10.1371/journal.pone.0152227)

Gude NM, Roberts CT, Kalionis B \& King RG 2004 Growth and function of the normal human placenta. Thrombosis Research 114 397-407. (https://doi.org/10.1016/j.thromres.2004.06.038)

Guillemot F, Nagy A, Auerbach A, Rossant J \& Joyner AL 1994 Essential role of Mash-2 in extraembryonic development. Nature 371 333-336. (https://doi.org/10.1038/371333a0)

Guillemot F, Caspary T, Tilghman SM, Copeland NG, Gilbert DJ, Jenkins NA, Anderson DJ, Joyner AL, Rossant J \& Nagy A 1995 Genomic imprinting of Mash2, a mouse gene required for trophoblast development. Nature Genetics 9 235-242. (https://doi.org/10.1038/ng0395-235)

Guionie O, Clottes E, Stafford K \& Burchell A 2003 Identification and characterisation of a new human glucose-6-phosphatase isoform. FEBS Letters 551 159-164. (https://doi.org/10.1016/s0014-5793(03)00903-7)

Hasan MZ, Ikawati M, Tocharus I, Kawaichi M \& Oka C 2015 Abnormal development of placenta in HtrA1-deficient mice. Developmental Biology 397 89-102. (https://doi.org/10.1016/j.ydbio.2014.10.015)

Hay Jr WW 1995 Regulation of placental metabolism by glucose supply. Reproduction, Fertility, and Development 7 365-375. (https://doi. org/10.1071/rd9950365)

He H, Perera BP, Ye A \& Kim J 2016 Parental and sexual conflicts over the Peg3 imprinted domain. Scientific Reports 6 38136. (https://doi. org/10.1038/srep38136)

He N, Lim SJ, Moreira De Mello JC, Navarro I, Bialecka M, Salvatori DCF, Van Der Westerlaken LAJ, Pereira LV \& Chuva De Sousa Lopes SM 2017 At term, XmO and XpO mouse placentas show differences in glucose metabolism in the trophectoderm-derived outer zone. Frontiers in Cell and Developmental Biology 5 63. (https://doi.org/10.3389/ fcell.2017.00063)

Heijkenskjold F \& Gemzell CA 1957 Glycogen content in the placenta in diabetic mothers. Acta Paediatrica 46 74-80. (https://doi. org/10.1111/j.1651-2227.1957.tb08633.x)

Hemberger M, Himmelbauer H, Ruschmann J, Zeitz C \& Fundele R 2000 CDNA subtraction cloning reveals novel genes whose temporal and spatial expression indicates association with trophoblast invasion. Developments in Biologicals 222 158-169.

Hermida MA, Dinesh Kumar J \& Leslie NR 2017 GSK3 and its interactions with the PI3K/AKT/mTOR signalling network. Advances in Biological Regulation 65 5-15. (https://doi.org/10.1016/j.jbior.2017.06.003)

Hwa V, Oh Y \& Rosenfeld RG 1999 The insulin-like growth factor-binding protein (IGFBP) superfamily. Endocrine Reviews 20 761-787. (https:// doi.org/10.1210/edrv.20.6.0382)

Jackman SM, Kong X \& Fant ME 2012 Plac1 (placenta-specific 1) is essential for normal placental and embryonic development. Molecular 
Reproduction and Development 79 564-572. (https://doi.org/10.1002/ mrd.22062)

Jensen AB, Tunster SJ \& John RM 2014 The significance of elevated placental PHLDA2 in human growth restricted pregnancies. Placenta $\mathbf{3 5}$ 528-532. (https://doi.org/10.1016/j.placenta.2014.04.018)

John RM, Ainscough JF, Barton SC \& Surani MA 2001 Distant cis-elements regulate imprinted expression of the mouse p57(Kip2) (Cdkn1c) gene: implications for the human disorder, Beckwith-Wiedemann syndrome. Human Molecular Genetics 10 1601-1609. (https://doi.org/10.1093/ $\mathrm{hmg} / 10.15 .1601)$

Jones HN, Woollett LA, Barbour N, Prasad PD, Powell TL \& Jansson T 2009 High-fat diet before and during pregnancy causes marked up-regulation of placental nutrient transport and fetal overgrowth in C57/BL6 mice. FASEB Journal 23 271-278. (https://doi.org/10.1096/fj.08-116889)

Kaiser S, Koch Y, Kuhnel E, Sharma N, Gellhaus A, Kuckenberg P, Schorle H \& Winterhager E 2015 Reduced gene dosage of Tfap2c impairs trophoblast lineage differentiation and alters maternal blood spaces in the mouse placenta. Biology of Reproduction 93 31. (https:// doi.org/10.1095/biolreprod.114.126474)

Kanzaki H, Crainie M, Lin H, Yui J, Guilbert LJ, Mori T \&Wegmann TG 1991 The in situ expression of granulocyte-macrophage colony-stimulating factor (GM-CSF) mRNA at the maternal-fetal interface. Growth Factors 5 69-74. (https://doi.org/10.3109/08977199109000272)

Karaplis AC, Luz A, Glowacki J, Bronson RT, Tybulewicz VL, Kronenberg HM \& Mulligan RC 1994 Lethal skeletal dysplasia from targeted disruption of the parathyroid hormone-related peptide gene. Genes and Development 8 277-289. (https://doi.org/10.1101/gad.8.3.277)

Kendall RL \& Thomas KA 1993 Inhibition of vascular endothelial cell growth factor activity by an endogenously encoded soluble receptor. PNAS 90 10705-10709. (https://doi.org/10.1073/pnas.90.22.10705)

Kozak KR, Abbott B \& Hankinson O 1997 ARNT-deficient mice and placental differentiation. Developmental Biology 191 297-305. (https:// doi.org/10.1006/dbio.1997.8758)

Kruger I, Vollmer M, Simmons DG, Elsasser HP, Philipsen S \& Suske G 2007 Sp1/Sp3 compound heterozygous mice are not viable: impaired erythropoiesis and severe placental defects. Developmental Dynamics 236 2235-2244. (https://doi.org/10.1002/dvdy.21222)

Kuckenberg P, Buhl S, Woynecki T, Van Furden B, Tolkunova E, Seiffe F, Moser M, Tomilin A, Winterhager E \& Schorle H 2010 The transcription factor TCFAP2C/AP-2gamma cooperates with CDX2 to maintain trophectoderm formation. Molecular and Cellular Biology 30 3310-3320. (https://doi.org/10.1128/MCB.01215-09)

Kuhnel E, Kleff V, Stojanovska V, Kaiser S, Waldschutz R, Herse F, Plosch T, Winterhager E \& Gellhaus A 2017 Placental-specific overexpression of sFlt-1 alters trophoblast differentiation and nutrient transporter expression in an IUGR mouse model. Journal of Cellular Biochemistry 118 1316-1329. (https://doi.org/10.1002/jcb.25789)

Kuroiwa Y, Kaneko-Ishino T, Kagitani F, Kohda T, Li LL, Tada M, Suzuki R, Yokoyama M, Shiroishi T, Wakana S et al. 1996 Peg3 imprinted gene on proximal chromosome 7 encodes for a zinc finger protein. Nature Genetics 12 186-190. (https://doi.org/10.1038/ng0296-186)

Kurz H, Zechner U, Orth A \& Fundele R 1999 Lack of correlation between placenta and offspring size in mouse interspecific crosses. Anatomy and Embryology 200 335-343. (https://doi.org/10.1007/s004290050284)

Laborda J 2000 The role of the epidermal growth factor-like protein dlk in cell differentiation. Histology and Histopathology 15 119-129. (https:// doi.org/10.14670/HH-15.119)

Lakisic G, Lebreton A, Pourpre R, Wendling O, Libertini E, Radford EJ, Le Guillou M, Champy MF, Wattenhofer-Donze M, Soubigou G et al. 2016 Role of the BAHD1 chromatin-repressive complex in placental development and regulation of steroid metabolism. PLoS Genetics 12 e1005898. (https://doi.org/10.1371/journal.pgen.1005898)

Lee S, Ye A \& Kim J 2015 DNA-binding motif of the imprinted transcription factor PEG3. PLOS ONE 10 e0145531. (https://doi.org/10.1371/journal. pone.0145531)

Lefebvre L 2012 The placental imprintome and imprinted gene function in the trophoblast glycogen cell lineage. Reproductive Biomedicine Online 25 44-57. (https://doi.org/10.1016/j.rbmo.2012.03.019)

Lefebvre L, Mar L, Bogutz A, Oh-Mcginnis R, Mandegar MA, Paderova J, Gertsenstein M, Squire JA \& Nagy A 2009 The interval between Ins2 and $\mathrm{Ascl} 2$ is dispensable for imprinting centre function in the murine Beckwith-Wiedemann region. Human Molecular Genetics 18 4255-4267. (https://doi.org/10.1093/hmg/ddp379)

Leighton PA, Ingram RS, Eggenschwiler J, Efstratiadis A \& Tilghman SM 1995 Disruption of imprinting caused by deletion of the H19 gene region in mice. Nature 375 34-39. (https://doi.org/10.1038/375034a0)

Lescisin KR, Varmuza S \& Rossant J 1988 Isolation and characterization of a novel trophoblast-specific cDNA in the mouse. Genes and Development 2 1639-1646. (https://doi.org/10.1101/gad.2.12a.1639)

Levine RJ, Lam C, Qian C, Yu KF, Maynard SE, Sachs BP, Sibai BM, Epstein FH, Romero R, Thadhani R et al. 2006 Soluble endoglin and other circulating antiangiogenic factors in preeclampsia. New England Journal of Medicine 355 992-1005. (https://doi.org/10.1056/NEJMoa055352)

Li Y \& Behringer RR 1998 Esx1 is an X-chromosome-imprinted regulator of placental development and fetal growth. Nature Genetics 20 309-311. (https://doi.org/10.1038/3129)

Li Y, Lemaire P \& Behringer RR 1997 Esx1, a novel X chromosome-linked homeobox gene expressed in mouse extraembryonic tissues and male germ cells. Developmental Biology 188 85-95. (https://doi.org/10.1006/ dbio.1997.8640)

Li L, Keverne EB, Aparicio SA, Ishino F, Barton SC \& Surani MA 1999 Regulation of maternal behavior and offspring growth by paternally expressed Peg3. Science 284 330-333. (https://doi.org/10.1126/ science.284.5412.330)

Li G, Xu C, Lin X, Qu L, Xia D, Hongdu B, Xia Y, Wang X, Lou Y, He Q et al. 2017 Deletion of Pdcd5 in mice led to the deficiency of placenta development and embryonic lethality. Cell Death and Disease 8 e2811. (https://doi.org/10.1038/cddis.2017.124)

Liu H, Wang Y, Zhang Y, Song Q, Di C, Chen G, Tang J \& Ma D 1999 TFAR19, a novel apoptosis-related gene cloned from human leukemia cell line TF-1, could enhance apoptosis of some tumor cells induced by growth factor withdrawal. Biochemical and Biophysical Research Communications 254 203-210. (https://doi.org/10.1006/ bbrc.1998.9893)

Lo S, Russell JC \& Taylor AW 1970 Determination of glycogen in small tissue samples. Journal of Applied Physiology 28 234-236. (https://doi. org/10.1152/jappl.1970.28.2.234)

Lopez MF, Dikkes P, Zurakowski D \& Villa-Komaroff L 1996 Insulin-like growth factor II affects the appearance and glycogen content of glycogen cells in the murine placenta. Endocrinology 137 2100-2108. (https://doi. org/10.1210/endo.137.5.8612553)

Maltepe E, Schmidt JV, Baunoch D, Bradfield CA \& Simon MC 1997 Abnormal angiogenesis and responses to glucose and oxygen deprivation in mice lacking the protein ARNT. Nature 386 403-407. (https://doi. org/10.1038/386403a0)

Manning BD \& Toker A 2017 AKT/PKB signaling: navigating the network. Cell 169 381-405. (https://doi.org/10.1016/j.cell.2017.04.001)

Matsubara S, Takizawa T \& Sato I 1999 Glucose-6-phosphatase is present in normal and pre-eclamptic placental trophoblasts: ultrastructural enzyme-histochemical evidence. Placenta 20 81-85. (https://doi. org/10.1053/plac.1998.0346)

Matsuoka S, Edwards MC, Bai C, Parker S, Zhang P, Baldini A, Harper JW \& Elledge SJ 1995 p57KIP2, a structurally distinct member of the p21Cip1 $\mathrm{Cdk}$ inhibitor family, is a candidate tumor suppressor gene. Genes and Development 9 650-662. (https://doi.org/10.1101/gad.9.6.650)

Mclellan AS, Fischer B, Dveksler G, Hori T, wynne F, Ball M, Okumura K, Moore T \& Zimmermann W 2005 Structure and evolution of the mouse pregnancy-specific glycoprotein (Psg) gene locus. BMC Genomics 64. (https://doi.org/10.1186/1471-2164-6-4)

Mcnamara GI, Creeth HDJ, Harrison DJ, Tansey KE, Andrews RM, Isles AR \& John RM 2018 Loss of offspring Peg3 reduces neonatal ultrasonic vocalizations and increases maternal anxiety in wild-type mothers. Human Molecular Genetics 27 440-450. (https://doi.org/10.1093/hmg/ $\mathrm{dd} \times 412$ )

Moore T, Constância M, Zubair M, Bailleul B, Feil R, Sasaki H \& Reik W 1997 Multiple imprinted sense and antisense transcripts, differential methylation and tandem repeats in a putative imprinting control region upstream of mouse Igf2. PNAS 94 12509-12514. (https://doi. org/10.1073/pnas.94.23.12509)

Mould A, Morgan MA, Li L, Bikoff EK \& Robertson EJ 2012 Blimp1/Prdm1 governs terminal differentiation of endovascular trophoblast giant cells and defines multipotent progenitors in the developing placenta. 
Genes and Development 26 2063-2074. (https://doi.org/10.1101/ gad.199828.112)

Nagy A, Gocza E, Diaz EM, Prideaux VR, Ivanyi E, Markkula M \& Rossant J 1990 Embryonic stem cells alone are able to support fetal development in the mouse. Development 110 815-821.

Nakayama KI \& Nakayama K 2006 Ubiquitin ligases: cell-cycle control and cancer. Nature Reviews: Cancer 6 369-381. (https://doi.org/10.1038/ nrc1881)

Napso T, Yong HEJ, Lopez-Tello J \& Sferruzzi-Perri AN 2018 The role of placental hormones in mediating maternal adaptations to support pregnancy and lactation. Frontiers in Physiology 9 1091. (https://doi. org/10.3389/fphys.2018.01091)

Naruse $M$, Ono $R$, Irie $M$, Nakamura $K$, Furuse T, Hino T, Oda $K$, Kashimura M, Yamada I, Wakana S et al. 2014 Sirh7/Ldoc1 knockout mice exhibit placental P4 overproduction and delayed parturition. Development 141 4763-4771. (https://doi.org/10.1242/dev.114520)

Nie G, Li Y \& Salamonsen LA 2005 Serine protease HtrA1 is developmentally regulated in trophoblast and uterine decidual cells during placental formation in the mouse. Developmental Dynamics 233 1102-1109. (https://doi.org/10.1002/dvdy.20399)

Nishiyama M, Nita A, Yumimoto K \& Nakayama KI 2015 FBXL12-mediated degradation of $\mathrm{ALDH} 3$ is essential for trophoblast differentiation during placental development. Stem Cells 33 3327-3340. (https://doi. org/10.1002/stem.2088)

O'Connell BA, Moritz KM, Walker DW \& Dickinson H 2013 Treatment of pregnant spiny mice at mid gestation with a synthetic glucocorticoid has sex-dependent effects on placental glycogen stores. Placenta 34 932-940. (https://doi.org/10.1016/j.placenta.2013.06.310)

Oh-Mcginnis R, Bogutz AB \& Lefebvre L 2011 Partial loss of Ascl2 function affects all three layers of the mature placenta and causes intrauterine growth restriction. Developmental Biology 351 277-286. (https://doi. org/10.1016/j.ydbio.2011.01.008)

Oka C, Tsujimoto R, Kajikawa M, Koshiba-Takeuchi K, Ina J, Yano M, Tsuchiya A, Ueta Y, Soma A, Kanda H et al. 2004 HtrA1 serine protease inhibits signaling mediated by Tgfbeta family proteins. Development $\mathbf{1 3 1}$ 1041-1053. (https://doi.org/10.1242/dev.00999)

Ono R, Nakamura K, Inoue K, Naruse M, Usami T, Wakisaka-Saito N, Hino T, Suzuki-Migishima R, Ogonuki N, Miki H et al. 2006 Deletion of Peg10, an imprinted gene acquired from a retrotransposon, causes early embryonic lethality. Nature Genetics 38 101-106. (https://doi. org/10.1038/ng1699)

Ouhilal S, Vuguin P, Cui L, Du XQ, Gelling RW, Reznik SE, Russell R, Parlow AF, Karpovsky C, Santoro N et al. 2012 Hypoglycemia, hyperglucagonemia, and fetoplacental defects in glucagon receptor knockout mice: a role for glucagon action in pregnancy maintenance. American Journal of Physiology: Endocrinology and Metabolism 302 E522-E531. (https://doi.org/10.1152/ajpendo.00420.2011)

Outhwaite JE, Natale BV, Natale DR \& Simmons DG 2015 Expression of aldehyde dehydrogenase family 1 , member $\mathrm{A} 3$ in glycogen trophoblast cells of the murine placenta. Placenta 36 304-311. (https://doi. org/10.1016/j.placenta.2014.12.002)

Parchem JG, Kanasaki K, Kanasaki M, Sugimoto H, Xie L, Hamano Y, Lee SB, Gattone VH, Parry S, Strauss JF et al. 2018 Loss of placental growth factor ameliorates maternal hypertension and preeclampsia in mice. Journal of Clinical Investigation 128 5008-5017. (https://doi. org/10.1172/JCI99026)

Pennisi DJ, Wilkinson L, Kolle G, Sohaskey ML, Gillinder K, Piper MJ, Mcavoy JW, Lovicu FJ \& Little MH 2007 Crim1KST264/KST264 mice display a disruption of the Crim1 gene resulting in perinatal lethality with defects in multiple organ systems. Developmental Dynamics 236 502-511. (https://doi.org/10.1002/dvdy.21015)

Pennisi DJ, Kinna G, Chiu HS, Simmons DG, Wilkinson L \& Little MH 2012 Crim1 has an essential role in glycogen trophoblast cell and sinusoidal-trophoblast giant cell development in the placenta. Placenta 33 175-182. (https://doi.org/10.1016/j.placenta.2011.12.014)

Perez-Garcia V, Fineberg E, Wilson R, Murray A, Mazzeo CI, Tudor C, Sienerth A, White JK, Tuck E, Ryder EJ et al. 2018 Placentation defects are highly prevalent in embryonic lethal mouse mutants. Nature $\mathbf{5 5 5}$ 463-468. (https://doi.org/10.1038/nature26002)

Prendergast CH, Parker KH, Gray R, Venkatesan S, Bannister P, CastroSoares J, Murphy KW, Beard RW, Regan L, Robinson S et al. 1999
Glucose production by the human placenta in vivo. Placenta 20 591-598. (https://doi.org/10.1053/plac.1999.0419)

Rampon C, Prandini MH, Bouillot S, Pointu H, Tillet E, Frank R, Vernet M \& Huber P 2005 Protocadherin 12 (VE-cadherin 2) is expressed in endothelial, trophoblast, and mesangial cells. Experimental Cell Research 302 48-60. (https://doi.org/10.1016/j.yexcr.2004.08.024)

Rampon C, Bouillot S, Climescu-Haulica A, Prandini MH, Cand F, Vandenbrouck Y \& Huber P 2008 Protocadherin 12 deficiency alters morphogenesis and transcriptional profile of the placenta. Physiological Genomics 34 193-204. (https://doi.org/10.1152/ physiolgenomics.00220.2007)

Redline RW, Chernicky CL, Tan HQ, Ilan J \& Ilan J 1993 Differential expression of insulin-like growth factor-II in specific regions of the late (post day 9.5) murine placenta. Molecular Reproduction and Development 36 121-129. (https://doi.org/10.1002/mrd.1080360202)

Reichmann J, Reddington JP, Best D, Read D, Ollinger R, Meehan RR \& Adams IR 2013 The genome-defence gene Tex19.1 suppresses LINE1 retrotransposons in the placenta and prevents intra-uterine growth retardation in mice. Human Molecular Genetics 22 1791-1806. (https:// doi.org/10.1093/hmg/ddt029)

Relaix F, Weng X, Marazzi G, Yang E, Copeland N, Jenkins N, Spence SE \& Sassoon D 1996 Pw1, a novel zinc finger gene implicated in the myogenic and neuronal lineages. Developmental Biology 177 383-396. (https://doi.org/10.1006/dbio.1996.0172)

Robb SA \& Hytten FE 1976 Placental glycogen. British Journal of Obstetrics and Gynaecology 83 43-53. (https://doi.org/10.1111/j.1471-0528.1976. tb00729.x)

Robertson SA, Roberts CT, Farr KL, Dunn AR \& Seamark RF 1999 Fertility impairment in granulocyte-macrophage colony-stimulating factordeficient mice. Biology of Reproduction 60 251-261. (https://doi. org/10.1095/biolreprod60.2.251)

Rossant J \& Cross JC 2001 Placental development: lessons from mouse mutants. Nature Reviews: Genetics 2 538-548. (https://doi. org/10.1038/35080570)

Rossant J, Guillemot F, Tanaka M, Latham K, Gertenstein M \& Nagy A 1998 Mash2 is expressed in oogenesis and preimplantation development but is not required for blastocyst formation. Mechanisms of Development $\mathbf{7 3}$ 183-191. (https://doi.org/10.1016/s0925-4773(98)00051-3)

Salas M, John R, Saxena A, Barton S, Frank D, Fitzpatrick G, Higgins MJ \& Tycko B 2004 Placental growth retardation due to loss of imprinting of Phlda2. Mechanisms of Development 121 1199-1210. (https://doi. org/10.1016/j.mod.2004.05.017)

Sarkar AA, Nuwayhid SJ, Maynard T, Ghandchi F, Hill JT, Lamantia AS \& Zohn IE 2014 Hectd1 is required for development of the junctional zone of the placenta. Developmental Biology 392 368-380. (https://doi. org/10.1016/j.ydbio.2014.05.007)

Sarkar AA, Sabatino JA, Sugrue KF \& Zohn IE 2016 Abnormal labyrinthine zone in the Hectd1-null placenta. Placenta 38 16-23. (https://doi. org/10.1016/j.placenta.2015.12.002)

Saxena A, Morozov P, Frank D, Musalo R, Lemmon MA, Skolnik EY \& Tycko B 2002 Phosphoinositide binding by the pleckstrin homology domains of $\mathrm{Ipl}$ and Tih1. Journal of Biological Chemistry 277 49935-49944. (https://doi.org/10.1074/jbc.M206497200)

Screen M, Dean W, Cross JC \& Hemberger M 2008 Cathepsin proteases have distinct roles in trophoblast function and vascular remodelling. Development 135 3311-3320. (https://doi.org/10.1242/dev.025627)

Sferruzzi-Perri AN, Macpherson AM, Roberts CT \& Robertson SA 2009 Csf2 null mutation alters placental gene expression and trophoblast glycogen cell and giant cell abundance in mice. Biology of Reproduction 81 207-221. (https://doi.org/10.1095/biolreprod.108.073312)

Sferruzzi-Perri AN, Vaughan OR, Coan PM, Suciu MC, Darbyshire R, Constancia M, Burton GJ \& Fowden AL 2011 Placental-specific Igf2 deficiency alters developmental adaptations to undernutrition in mice. Endocrinology 152 3202-3212. (https://doi.org/10.1210/en.2011-0240)

Sferruzzi-Perri AN, Vaughan OR, Haro M, Cooper WN, Musial B, Charalambous M, Pestana D, Ayyar S, Ferguson-Smith AC, Burton GJ et al. 2013 An obesogenic diet during mouse pregnancy modifies maternal nutrient partitioning and the fetal growth trajectory. FASEB Journal 27 3928-3937. (https://doi.org/10.1096/fj.13-234823)

Sharma A, Lacko LA, Argueta LB, Glendinning MD \& Stuhlmann H 2019 miR-126 regulates glycogen trophoblast proliferation and DNA 
methylation in the murine placenta. Developmental Biology 449 21-34. (https://doi.org/10.1016/j.ydbio.2019.01.019)

Sferruzzi-Perri AN, Lopez-Tello J, Fowden AL \& Constancia M 2016 Maternal and fetal genomes interplay through phosphoinositol 3-kinase(PI3K)-p110alpha signaling to modify placental resource allocation. PNAS 113 11255-11260. (https://doi.org/10.1073/ pnas.1602012113)

Sferruzzi-Perri AN, Sandovici I, Constancia M \& Fowden AL 2017 Placental phenotype and the insulin-like growth factors: resource allocation to fetal growth. Journal of Physiology 595 5057-5093. (https:// doi.org/10.1113/JP273330)

Sharma N, Kubaczka C, Kaiser S, Nettersheim D, Mughal SS, Riesenberg S, Holzel M, Winterhager E \& Schorle H 2016 Tpbpa-Cre-mediated deletion of TFAP2C leads to deregulation of Cdkn1a, Akt1 and the ERK pathway, causing placental growth arrest. Development 143 787-798. (https://doi.org/10.1242/dev.128553)

Sibilia M \& Wagner EF 1995 Strain-dependent epithelial defects in mice lacking the EGF receptor. Science 269 234-238. (https://doi.org/10.1126/ science.7618085)

Sibley CP, Coan PM, Ferguson-Smith AC, Dean W, Hughes J, Smith P, Reik W, Burton GJ, Fowden AL \& Constância M 2004 Placental-specific insulin-like growth factor 2 (Igf2) regulates the diffusional exchange characteristics of the mouse placenta. PNAS 101 8204-8208. (https:// doi.org/10.1073/pnas.0402508101)

Simmons DG \& Cross JC 2005 Determinants of trophoblast lineage and cell subtype specification in the mouse placenta. Developmental Biology 284 12-24. (https://doi.org/10.1016/j.ydbio.2005.05.010)

Simmons DG, Fortier AL \& Cross JC 2007 Diverse subtypes and developmental origins of trophoblast giant cells in the mouse placenta. Developmental Biology 304 567-578. (https://doi.org/10.1016/j. ydbio.2007.01.009)

Simmons DG, Natale DR, Begay V, Hughes M, Leutz A \& Cross JC 2008a Early patterning of the chorion leads to the trilaminar trophoblast cell structure in the placental labyrinth. Development 135 2083-2091. (https://doi.org/10.1242/dev.020099)

Simmons DG, Rawn SM, Davies A, Hughes M \& Cross JC 2008b Spatial and temporal expression of the 23 murine prolactin/placental lactogenrelated genes is not associated with their position in the locus. BMC Genomics 9 352. (https://doi.org/10.1186/1471-2164-9-352)

Singh VP, Alex JL, Lakshmi BJ, Sailasree SP, Raj TA \& Kumar S 2015 Role of mouse Wdr13 in placental growth; a genetic evidence for lifetime body weight determination by placenta during development. Scientific Reports 5 13371. (https://doi.org/10.1038/srep13371)

Soares MJ \& Hunt JS 2014 Placenta and Trophoblast: Methods and Protocols. Humana Press.

Takagi N \& Sasaki M 1975 Preferential inactivation of the paternally derived $\mathrm{X}$ chromosome in the extraembryonic membranes of the mouse. Nature 256 640-642. (https://doi.org/10.1038/256640a0)

Takahashi K, Kobayashi T \& Kanayama N 2000 p57(Kip2) regulates the proper development of labyrinthine and spongiotrophoblasts. Molecular Human Reproduction 6 1019-1025. (https://doi.org/10.1093/ molehr/6.11.1019)

Takao T, Asanoma K, Tsunematsu R, Kato K \& Wake N 2012 The maternally expressed gene Tssc3 regulates the expression of MASH2 transcription factor in mouse trophoblast stem cells through the AKT-Sp1 signaling pathway. Journal of Biological Chemistry 287 42685-42694. (https://doi. org/10.1074/jbc.M112.388777)

Tarkowski AK, Witkowska A \& Opas J 1977 Development of cytochalasin in B-induced tetraploid and diploid/tetraploid mosaic mouse embryos. Journal of Embryology and Experimental Morphology 41 47-64.

Tayade C, Hilchie D, He H, Fang Y, Moons L, Carmeliet P, Foster RA \& Croy BA 2007 Genetic deletion of placenta growth factor in mice alters uterine NK cells. Journal of Immunology 178 4267-4275. (https://doi. org/10.4049/jimmunol.178.7.4267)

Tesser RB, Scherholz PL, Do Nascimento L \& Katz SG 2010 Trophoblast glycogen cells differentiate early in the mouse ectoplacental cone: putative role during placentation. Histochemistry and Cell Biology 134 83-92. (https://doi.org/10.1007/s00418-010-0714-x)

Thiaville MM, Huang JM, Kim H, Ekram MB, Roh TY \& Kim J 2013 DNAbinding motif and target genes of the imprinted transcription factor PEG3. Gene 512 314-320. (https://doi.org/10.1016/j.gene.2012.10.005)
Tran H, Bustos D, Yeh R, Rubinfeld B, Lam C, Shriver S, Zilberleyb I, Lee MW, Phu L, Sarkar AA et al. 2013 HectD1 E3 ligase modifies adenomatous polyposis coli (APC) with polyubiquitin to promote the APC-axin interaction. Journal of Biological Chemistry 288 3753-3767. (https://doi.org/10.1074/jbc.M112.415240)

Tsoi SC, Cale JM, Bird IM \& Kay HH 2003 cDNA microarray analysis of gene expression profiles in human placenta: up-regulation of the transcript encoding muscle subunit of glycogen phosphorylase in preeclampsia. Journal of the Society for Gynecologic Investigation 10 496-502. (https://doi.org/10.1016/s1071-5576(03)00154-0)

Tunster SJ, Tycko B \& John RM 2010 The imprinted Phlda2 gene regulates extraembryonic energy stores. Molecular and Cellular Biology 30 295-306. (https://doi.org/10.1128/MCB.00662-09)

Tunster SJ, Van De Pette M \& John RM 2011 Fetal overgrowth in the Cdkn1c mouse model of Beckwith-Wiedemann syndrome. Disease Models and Mechanisms 4 814-821. (https://doi.org/10.1242/dmm.007328)

Tunster SJ, Van De Pette M \& John RM 2012 Impact of genetic background on placental glycogen storage in mice. Placenta 33 124-127. (https:// doi.org/10.1016/j.placenta.2011.11.011)

Tunster SJ, Jensen AB \& John RM 2013 Imprinted genes in mouse placental development and the regulation of fetal energy stores. Reproduction $\mathbf{1 4 5}$ R117-R137. (https://doi.org/10.1530/REP-12-0511)

Tunster SJ, Van De Pette M \& John RM 2014 Isolating the role of elevated Phlda2 in asymmetric late fetal growth restriction in mice. Disease Models and Mechanisms 7 1185-1191. (https://doi.org/10.1242/ dmm.017079)

Tunster SJ, Creeth HD \& John RM 2015 The imprinted Phlda2 gene modulates a major endocrine compartment of the placenta to regulate placental demands for maternal resources. Developments in Biologicals.

Tunster SJ, Mcnamara GI, Creeth HDJ \& John RM 2016 Increased dosage of the imprinted Ascl2 gene restrains two key endocrine lineages of the mouse Placenta. Developmental Biology 418 55-65. (https://doi. org/10.1016/j.ydbio.2016.08.014)

Tunster SJ, Boque-Sastre R, Mcnamara GI, Hunter SM, Creeth HDJ \& John RM 2018 Peg3 deficiency results in sexually dimorphic losses and gains in the normal repertoire of placental hormones. Frontiers in Cell and Developmental Biology 6 123. (https://doi.org/10.3389/ fcell.2018.00123)

Van Schaftingen E \& Gerin I 2002 The glucose-6-phosphatase system. Biochemical Journal 362 513-532. (https://doi.org/10.1042/02646021:3620513)

Villee CA 1953 The metabolism of human placenta in vitro. Journal of Biological Chemistry 205 113-123.

Vincent SD, Dunn NR, Sciammas R, Shapiro-Shalef $M$, Davis $M M$, Calame K, Bikoff EK \& Robertson EJ 2005 The zinc finger transcriptional repressor Blimp1/Prdm1 is dispensable for early axis formation but is required for specification of primordial germ cells in the mouse. Development 132 1315-1325. (https://doi.org/10.1242/dev.01711)

Wang Y, Li X, Wang L, Ding P, Zhang Y, Han W \& Ma D 2004 An alternative form of paraptosis-like cell death, triggered by TAJ/TROY and enhanced by PDCD5 overexpression. Journal of Cell Science 117 1525-1532. (https://doi.org/10.1242/jcs.00994)

Wang SS, Aurora AB, Johnson BA, Qi XX, Mcanally J, Hill JA, Richardson JA, Bassel-Duby R \& Olson EN 2008 The endothelial-specific microRNA miR-126 governs vascular integrity and angiogenesis. Developmental Cell 15 261-271. (https://doi.org/10.1016/j.devcel.2008.07.002)

Watson ED \& Cross JC 2005 Development of structures and transport functions in the mouse placenta. Physiology 20 180-193. (https://doi. org/10.1152/physiol.00001.2005)

Wilkinson L, Gilbert T, Kinna G, Ruta LA, Pennisi D, Kett M \& Little MH 2007 Crim1KST264/KST264 mice implicate Crim1 in the regulation of vascular endothelial growth factor-A activity during glomerular vascular development. Journal of the American Society of Nephrology $\mathbf{1 8}$ 1697-1708. (https://doi.org/10.1681/ASN.2006091012)

Wislocki GB \& Bennett HS 1943 The histology and cytology of the human and monkey placenta, with special reference to the trophoblast. American Journal of Anatomy 73 335-449. (https://doi.org/10.1002/ aja.1000730303)

Withington SL, Scott AN, Saunders DN, Lopes Floro K, Preis II, Michalicek J, Maclean K, Sparrow DB, Barbera JP \& Dunwoodie SL 2006 Loss of Cited2 affects trophoblast formation and vascularization 
of the mouse placenta. Developmental Biology 294 67-82. (https://doi. org/10.1016/j.ydbio.2006.02.025)

Wysolmerski JJ \& Stewart AF 1998 The physiology of parathyroid hormonerelated protein: an emerging role as a developmental factor. Annual Review of Physiology 60 431-460. (https://doi.org/10.1146/annurev. physiol.60.1.431)

Yang ZZ, Tschopp O, Hemmings-Mieszczak M, Feng J, Brodbeck D, Perentes E \& Hemmings BA 2003 Protein kinase B alpha/Akt1 regulates placental development and fetal growth. Journal of Biological Chemistry 278 32124-32131. (https://doi.org/10.1074/jbc.M302847200)

Yevtodiyenko A \& Schmidt JV 2006 Dlk1 expression marks developing endothelium and sites of branching morphogenesis in the mouse embryo and placenta. Developmental Dynamics 235 1115-1123. (https://doi. org/10.1002/dvdy.20705)

Yin Z, Haynie J, Yang X, Han B, Kiatchoosakun S, Restivo J, Yuan S, Prabhakar NR, Herrup K, Conlon RA et al. 2002 The essential role of Cited2, a negative regulator for HIF-1alpha, in heart development and neurulation. PNAS 99 10488-10493. (https://doi.org/10.1073/ pnas.162371799)

Yu JS \& Cui W 2016 Proliferation, survival and metabolism: the role of $\mathrm{PI} 3 \mathrm{~K} / \mathrm{AKT} / \mathrm{mTOR}$ signalling in pluripotency and cell fate determination. Development 143 3050-3060. (https://doi.org/10.1242/dev.137075)

Yung HW, Calabrese S, Hynx D, Hemmings BA, Cetin I, CharnockJones DS \& Burton GJ 2008 Evidence of placental translation inhibition and endoplasmic reticulum stress in the etiology of human intrauterine growth restriction. American Journal of Pathology 173 451-462. (https:// doi.org/10.2353/ajpath.2008.071193)

Zhang J, Wang C, Terroni PL, Cagampang FR, Hanson M \& Byrne CD 2005 High-unsaturated-fat, high-protein, and low-carbohydrate diet during pregnancy and lactation modulates hepatic lipid metabolism in female adult offspring. American Journal of Physiology: Regulatory, Integrative and Comparative Physiology 288 R112-R118. (https://doi.org/10.1152/ ajpregu.00351.2004)

Zhang J, Zhang F, Didelot X, Bruce KD, Cagampang FR, Vatish M, Hanson M, Lehnert H, Ceriello A \& Byrne CD 2009 Maternal high fat diet during pregnancy and lactation alters hepatic expression of insulin like growth factor- 2 and key microRNAs in the adult offspring. BMC Genomics 10 478. (https://doi.org/10.1186/1471-2164-10-478)

Zhang Q, Hao J \& Li G 2019 Deletion of Prl7d1 causes placental defects at mid-pregnancy in mice. Molecular Reproduction and Development $\mathbf{8 6}$ 696-713. (https://doi.org/10.1002/mrd.23148)

Zheng-Fischhofer $Q$, Kibschull $M$, Schnichels $M$, Kretz $M$, PetraschParwez E, Strotmann J, Reucher H, Lynn BD, Nagy JI, Lye SJ et al. 2007 Characterization of connexin31.1-deficient mice reveals impaired placental development. Developmental Biology 312 258-271. (https:// doi.org/10.1016/j.ydbio.2007.09.025)

Zheng N, Wang Z \& Wei W 2016 Ubiquitination-mediated degradation of cell cycle-related proteins by F-box proteins. International Journal of Biochemistry and Cell Biology 73 99-110. (https://doi.org/10.1016/j. biocel.2016.02.005)

Received 7 January 2020

First decision 18 February 2020

Revised manuscript received 5 March 2020

Accepted 19 March 2020 